\title{
Ocean wave sources of seismic noise
}

\author{
Fabrice Ardhuin, ${ }^{1}$ Eleonore Stutzmann, ${ }^{2}$ Martin Schimmel, ${ }^{3}$ and Anne Mangeney ${ }^{4}$ \\ Received 12 January 2011; revised 3 May 2011; accepted 7 June 2011; published 8 September 2011.
}

[1] Noise with periods 3 to $10 \mathrm{~s}$, ubiquitous in seismic records, is expected to be mostly generated by pairs of ocean wave trains of opposing propagation directions with half the seismic frequency. Here we present the first comprehensive numerical model of microseismic generation by random ocean waves, including ocean wave reflections. Synthetic and observed seismic spectra are well correlated $(r>0.85)$. On the basis of the model results, noise generation events can be clustered in three broad classes: wind waves with a broad directional spectrum (class I), sea states with a significant contribution of coastal reflections (class II), and the interaction of two independent wave systems (class III). At seismic stations close to western coasts, noise generated by class II sources generally dominates, but it is intermittently outshined by the intense class III sources, limiting the reliability of seismic data as a proxy for storm climates. The modeled seismic noise critically depends on the damping of seismic waves. At some mid-ocean island stations, low seismic damping is necessary to reproduce the observed high level and smoothness of noise time series that result from a spatial integration of sources over thousands of kilometers. In contrast, some coastal stations are only sensitive to noise within a few hundreds of kilometers. This revelation of noise source patterns worldwide provides a wealth of information for seismic studies, wave climate applications, and new constraints on the possible directional distribution of wave energy.

Citation: Ardhuin, F., E. Stutzmann, M. Schimmel, and A. Mangeney (2011), Ocean wave sources of seismic noise, J. Geophys. Res., 116, C09004, doi:10.1029/2011JC006952.

\section{Introduction}

[2] Ocean waves have long been suspected to cause microseisms [Wiechert, 1904] with a dominant seismic peak at twice the wave frequency [Bernard, 1941]. A realistic theory was only given by Longuet-Higgins [1950] and extended to random waves by Hasselmann [1963]. Seismic noise sources could be located with a fair degree of accuracy using large aperture seismic arrays, as demonstrated by Haubrich and McCamy [1969], and the contributions of the various seismic wave modes was also revealed, showing that fundamental Rayleigh and Love modes tend to dominate at frequencies less than $0.2 \mathrm{~Hz}$. Still, without a full quantitative verification, the debate lingers on the distribution of noise sources, including the relative importance of shoreline reflections, and the general validity of the LonguetHiggins-Hasselmann theory.

\footnotetext{
${ }^{1}$ Laboratoire d'Océanographie Spatiale, Institut Français de Recherche pour l'Exploitation de la Mer, Plouzane, France.

${ }^{2}$ Departement de Sismologie, Institut de Physique du Globe de Paris, Sorbonne Paris-Cité, Paris, France.

${ }^{3}$ Department of Structure and Dynamics of the Earth, Institute of Earth Sciences Jaume Almera, Consejo Superior de Investigaciones Científicas, Barcelona, Spain.

${ }^{4}$ Departement de Sismologie, Institut de Physique du Globe de Paris, Université Paris VII - Denis Diderot, Sorbonne Paris-Cité, Paris, France.

Copyright 2011 by the American Geophysical Union. 0148-0227/11/2011JC006952
}

[3] A first detailed verification of this theory using the output of a numerical wave model was only performed recently by Kedar et al. [2008]. This work was limited to northwest Atlantic sources and coastal reflections were not included, although they are probably important for other regions [e.g., Zopf et al., 1976; Chevrot et al., 2007]. Also, recent progress in numerical wave modeling [WISE Group, 2007; Ardhuin et al., 2010] should also result in more accurate seismic noise applications.

[4] Here we extend the work by Kedar et al. [2008] to the global ocean and also take into account coastal reflections. We show that a single global model of seismic noise energy radiation, with realistic ocean wave reflections and seismic attenuation factors, can explain most observed seismic noise in spectra of vertical ground motions. This validated model is then used to discuss the importance of various classes of sea state that contribute to seismic sources and to explain the different seismic noise climates observed at a few selected seismic stations.

[5] Our model is based on a state-of-the-art numerical wave model [Ardhuin et al., 2010] to which coastal reflection was added, but its seismic part is simplified in many aspects. Also, we only model the spectral distribution of the seismic wave energy, without any phase information. This paper is organized as follows. After a review of the noise generation theory, the practical modeling of microseisms is described in section 2 . The validity of numerical wave models for the estimation of seismic noise is discussed in section 3. General model results are then presented in 


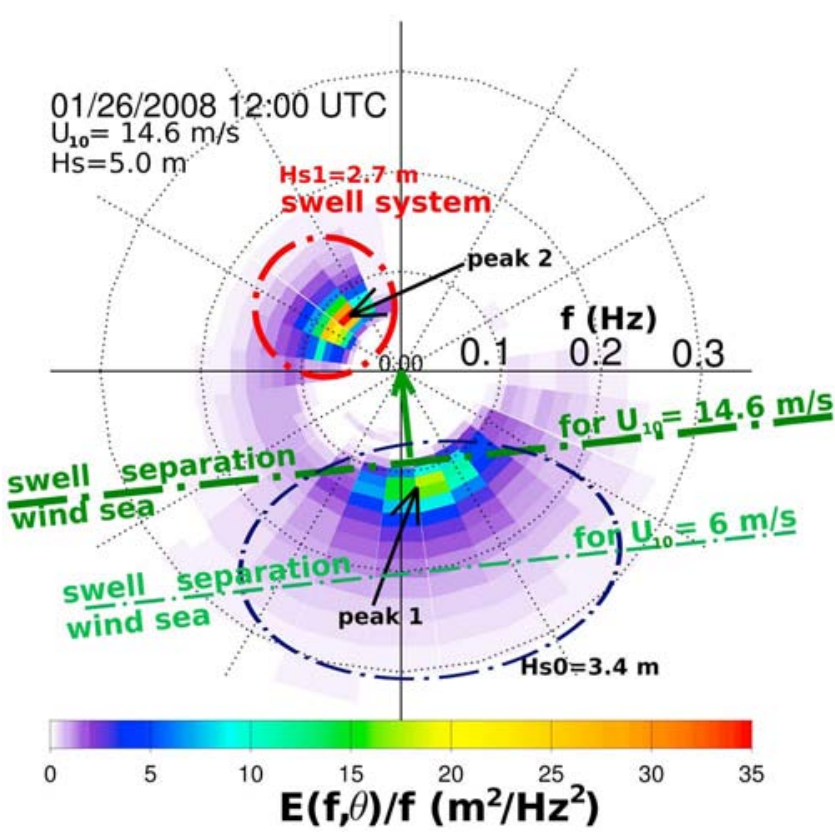

Figure 1. Example of a modeled frequency directional spectrum represented in polar coordinates $f$ and $\theta$. The directions are the directions from where the waves propagate. This spectrum corresponds to a situation offshore of California at $34^{\circ} \mathrm{N} 125.5^{\circ} \mathrm{W}$, with strong winds from the south (green arrow) and swells from the northwest. The separation between wind-sea and swell is shown by the green dash-dotted line, which corresponds to frequencies $f=0.09 \mathrm{~Hz}$ for waves in the wind direction. For a weaker wind, the separation would occur at higher frequency (e.g., $0.21 \mathrm{~Hz}$ for $U_{10}=6 \mathrm{~m} / \mathrm{s}$ ), and what is now the wind-sea peak (peak 1) would then be another swell peak.

section 4 with validation at a few selected locations in section 5. Perspectives for improved models are given in section 6 .

\section{Seismic Noise Modeling}

\subsection{Theory}

[6] Owing to weak nonlinear effects, any pair of monochromatic ocean wave trains force water motions with frequencies $f_{2}$ and wave number $\mathbf{k}_{2}$ that are the sum of the free ocean wave train frequencies and wave numbers. For equal frequency but opposing directions, the forcing is equivalent to horizontally uniform pressure oscillations applied at the sea surface [Miche, 1944]. Including water compressibility effects, Longuet-Higgins [1950] showed how seismic waves are excited with wave number $\mathbf{k}_{s}=\mathbf{k}_{2}$ and frequency $f_{s}=f_{2}$. Here we use the extension to random waves given by Hasselmann [1963]. Proposed extensions to waves in finite depth [Webb, 2007] and low frequencies [Tanimoto, 2010] have no influence on the results presented here.

[7] The local sea state can be described by the directional wave spectrum $F(f, \theta)$. For practical purposes, this spectrum can be written as a product of the frequency spectrum $E(f)$, which is the power spectrum of the sea surface vertical displacement usually obtained from the heave time series of a buoy, and a directional distribution $M(f, \theta)$ which gives, at each frequency the distribution of the surface elevation variance over all directions, from 0 to $2 \pi$ and normalizes such that, for any $f$,

$$
\int_{0}^{2 \pi} M(f, \theta) \mathrm{d} \theta=1 .
$$

Hence, we have $F(f, \theta)=E(f) M(f, \theta)$. From this spectrum, Hasselmann [1963] gives the wave-induced pressure at near-zero wave number $\left(\mathbf{k}_{2} \simeq 0\right)$ and twice the wave frequency $\left(f_{2}=2 f\right)$. The quasi-equality $\mathbf{k}_{2} \simeq 0$ means that $\mathbf{k}_{2}$ is much less than the surface gravity wave number, and thus practically zero for the evaluation of the spectral density of the wave-induced pressure. Obviously $2 \pi f_{2} / k_{2}$ is still finite and equal to the seismic phase speed.

[8] Hasselmann [1963, equation (2.15)] (see Appendix A for details) can be transformed into

$$
F_{p 3 D}\left(f_{2}=2 f, \mathbf{k}_{2} \simeq 0\right)=\rho_{w}^{2} g^{2} f_{2} E^{2}(f) I(f),
$$

where $F_{p 3 D}$ has S.I. units of $\mathrm{Pa}^{2} \mathrm{~m}^{2}$ s. In the following, we will also discuss the two-dimensional frequency-integrated spectrum $F_{p 2 D}$ with S.I. units of $\mathrm{Pa}^{2} \mathrm{~m}^{2}$.

[9] $I(f)$ is a nondimensional function that depends only on the wave energy distribution $M$ over the directions $\theta$,

$$
I(f)=\int_{0}^{\pi} M(f, \theta) M(f, \theta+\pi) \mathrm{d} \theta .
$$

We note that Farrell and Munk [2008] used a definition of $I$ with an integral over $[0,2 \pi]$ which gives values of $I$ that are twice as large. Since the integrand has a periodicity of $\pi$, we prefer to integrate only over $[0, \pi]$, which simplifies the final expression for the noise source. This directional integral forbids generic and accurate relationships between the significant oceanic wave height

$$
H_{s}=4 \sqrt{\int_{0}^{\infty} E(f) \mathrm{d} f}
$$

and the seismic sources.

[10] Using common oceanographic practice, as illustrated by Figure 1, we define the wind-sea as the part of the sea state with directions within $90^{\circ}$ from the wind direction and associated with peaks for which the phase speeds are less than 1.2 times $U_{10}$, the wind speed at $10 \mathrm{~m}$ height. That second condition corresponds, in deep water, to $g /(2 \pi f)<$ $1.2 U_{10}$. This association of spectral components with a given peak is done using an watershed-type algorithm: all components that lie on a path of monotonically decreasing energy from the peak are associated with it. As a result, the wind-sea peak often involves some energy of wave components that would, by themselves, be rather identified as swell. Swells are all other wave components, which includes components generated by wind-sea reflection from shorelines. The swell part of the wave spectrum is usually further partitioned into different swell systems when the wave spectrum contains several narrow peaks. These peaks generally correspond to waves generated by different storms [e.g., Hanson and Phillips, 2001].

[11] In general, $I$ is largest when swell from a distant source propagates against the locally generated wind-sea 

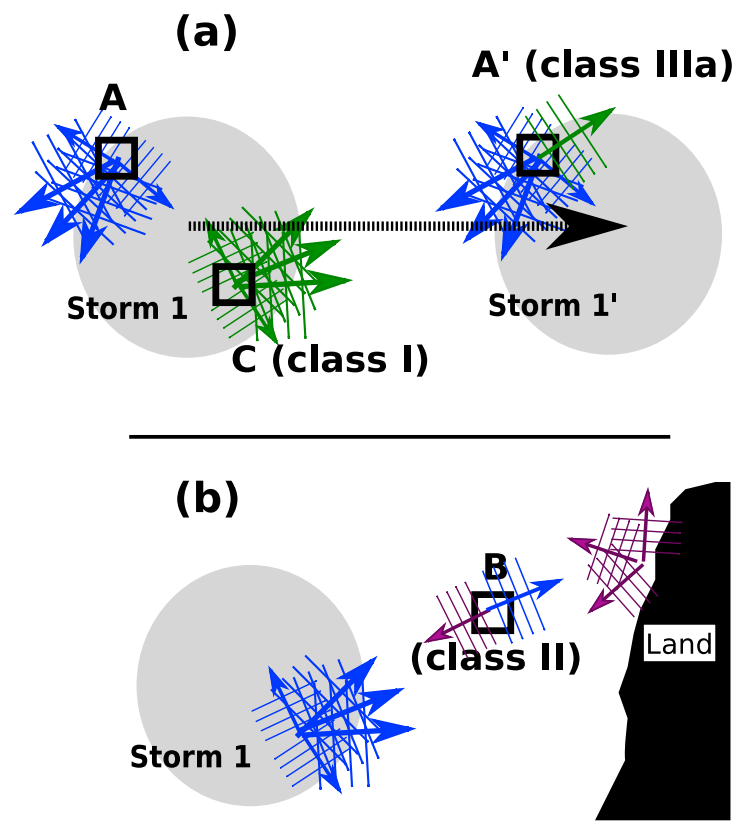

(c)

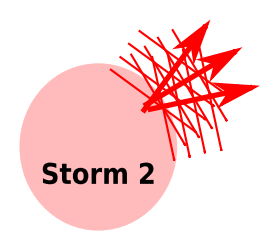

A (class IIIb)

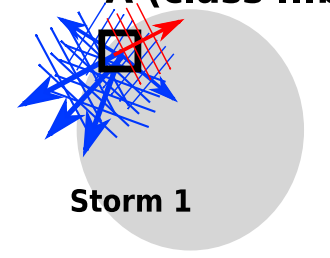

Figure 2. Schematic of wave conditions in noise-generating situations. (a) Storm 1 is rapidly moving so that waves generated at $\mathrm{C}$ become swell that can meet the wind-sea at point $\mathrm{A}^{\prime}$. In this case the noise generated by the local wind-sea alone at point $\mathrm{C}$ (class I) can be much stronger at point $\mathrm{A}^{\prime}$ because of the wider directional distribution. (b) Noise generated when waves reflect off the coast (class II), and (c) noise generated when waves from two distinct storms cross, here at point A (class III).

[e.g., Kedar et al., 2008], in cases with rapidly turning winds [e.g., Gerstoft et al., 2006], or when waves are reflected off the shoreline [e.g., Bromirski et al., 1999]. Yet, I can still be significant for a wind that is constant and uniform, due to the generation of waves at very oblique angles (more than $90^{\circ}$ ) relative to the wind [Donelan et al., 1985; Long and Resio, 2007]. Figure 2 summarizes these different conditions. The directional distribution of the wave energy is thus a critical characteristic of the wavefield, and the expected features of modeled and real sea states are discussed in section 3 . The wave-induced pressure given by equation (2) may generate all sorts of seismic modes, including surface and body waves, because all seismic waves have very small wave numbers $k_{s} \ll k$, for which the spectral density of the waveinduced pressure is uniform. Following Longuet-Higgins, we will now restrict our scope to the fundamental mode of seismic Rayleigh waves which is dominant in the band of periods from 5 to $12 \mathrm{~s}$ [Haubrich and McCamy, 1969; Koper et al., 2010].
[12] With a uniform rock density $\rho_{s}$ and shear wave velocity $\beta$, the wave-induced surface pressure yields an equivalent source for the power spectrum of the vertical ground displacement [Hasselmann, 1963],

$$
S_{D F}\left(f_{s}\right) \simeq \frac{2 \pi f_{s} \widetilde{C}}{\rho_{s}^{2} \beta^{5}} F_{p 3 D}\left(\mathbf{k}_{2} \simeq 0, f_{s}\right),
$$

where the nondimensional coefficient $0.05<\widetilde{C}<0.84$ varies with the ratio of the acoustic wavelength to water depth $D$. We use $\widetilde{C}=c_{1}^{2}+c_{2}^{2}$, where $c_{1}$ and $c_{2}$ are the amplitude response functions for the first two normal modes, taken from Longuet-Higgins [1950]. For $f_{s}=0.15 \mathrm{~Hz}, \widetilde{C}$ peaks at $D \simeq 2300 \mathrm{~m}$, and this depth varies inversely proportionally to $f_{s}$. The units of $S_{D F}\left(f_{s}\right)$ are meters times seconds. For display purposes we also define

$$
S_{D F, I}=\int_{0.08 \mathrm{~Hz}}^{0.32 \mathrm{~Hz}} S_{D F}\left(f_{s}\right) \mathrm{d} f_{s},
$$

with units of meters. $S_{D F, I}$ is the local contribution to the vertical ground displacement variance, which has units of $\mathrm{m}^{2}$, per unit distance of the seismic wave propagation.

[13] From this we obtain $F_{\delta}\left(f_{s}\right)$, the power spectrum of the vertical ground displacement, at any seismic station of latitude $\lambda$ and longitude $\phi$, as the instantaneous combination of sources at $\left(\lambda^{\prime}, \phi^{\prime}\right)$. We propagate the seismic (Rayleigh) waves in a vertically symmetric earth model, neglecting all three-dimensional propagation effects, and parameterizing seismic wave scattering and dissipation with a uniform quality factor $Q$. The seismic power attenuation is thus a function of the spherical distance $\Delta$ between source and station, giving,

$$
F_{\delta}\left(\lambda, \phi, f_{s}\right)=\int_{-\pi / 2}^{\pi / 2} \int_{0}^{2 \pi} \frac{S_{D F}\left(f_{s}\right)}{R_{E} \sin \Delta} \mathrm{e}^{-2 \pi f_{s} \Delta R_{E} /(U Q)}\left(R_{E}^{2} \sin \phi^{\prime} \mathrm{d} \lambda^{\prime} \mathrm{d} \phi^{\prime}\right),
$$

with $R_{E}$ being the Earth radius and $U$ being the seismic group velocity. The bracketed term $\left(R_{E}^{2} \sin \phi^{\prime} \mathrm{d} \lambda^{\prime} \mathrm{d} \phi^{\prime}\right)$ is the Earth surface area element. $R_{E} \sin \Delta$ in the denominator is the geometrical spreading factor for wave energy that follows geodesics on the sphere [e.g., Kanamori and Given, 1981], replacing the distance $R_{E} \Delta$ used in flat Earth models [e.g., Hasselmann, 1963]. This expression assumes that $U Q$ is the same for all the seismic modes.

[14] Our model yields the power spectrum of the ground displacement, and for quantitative validation we will use the root mean square (RMS) vertical ground displacement

$$
\delta_{\mathrm{RMS}}(\lambda, \phi)=\sqrt{\int_{0.08 \mathrm{~Hz}}^{0.32 \mathrm{~Hz}} F_{\delta}\left(\lambda, \phi, f_{s}\right) \mathrm{d} f_{s}} .
$$

For infinitely high $Q$, i.e., without loss of seismic energy, a source of power $S_{D F, I}=10^{-16} \mathrm{~m}$ uniform over a square of 100 by $100 \mathrm{~km}$ located at a distance of $1000 \mathrm{~km}$, gives a displacement variance $\delta_{\mathrm{RMS}}^{2}=1 \mu \mathrm{m}^{2}$. With typical values of the parameters in equation (5), such a source can be given by a wave-induced pressure $F_{p 2 D} \simeq 3 \times 10^{4} \mathrm{hPa}^{2} \mathrm{~m}^{2}$, which is of the order of the highest sources given by our model. The variance actually recorded at a station is the sum of the variances contributed by all such elementary squares. Hence 
the noise level increases significantly with the spatial extension of the source area.

\subsection{Numerical Wave Modeling for Seismic Noise}

[15] Wave spectra are provided by a numerical wave model based on the version 3.14 of the WAVEWATCH III ${ }^{(R)}$ code [Tolman, 1991, 2009], using improved parameterizations for wind-wave generation and dissipation. These parameterizations have been carefully adjusted to reproduce as well as possible a wide variety of observations, including directional properties [Ardhuin et al., 2010; Delpey et al., 2010]. The better quality of these parameterization has been validated independently by 2 years of routine analysis and forecasting [e.g., Bidlot, 2009] (see http://tinyurl.com/3vpr7jd). Our global model, with a resolution of $0.5^{\circ}$ in latitude and longitude, is forced by 6-hourly wind analysis from the European Centre for Medium range Weather Forecasting (ECMWF), daily ECMWF sea ice concentration analysis, and monthly Southern Ocean distribution statistics for small icebergs [Tournadre et al., 2008]. Adding icebergs was critical for improving the model quality for latitudes south of $45^{\circ} \mathrm{S}$ [Ardhuin et al., 2011]. Using higher spatial resolution for coastal areas did not significantly change the model results. We use a spectral resolution with 24 directions by 31 frequency, and the noise sources are only stored for 15 frequencies $(0.04$ to $0.17 \mathrm{~Hz})$ in order to limit the amount of stored information. All the computed seismic noise sources are available in NetCDF format from the IOWAGA project (http://tinyurl.com/yetsofy), and cover the years 1994 to 2010, with an ongoing extension into the future.

[16] A novel aspect of our wave model is the introduction of reflections both at the ocean-land boundary, the usual shoreline, and also around icebergs, which provide additional "shorelines," which are the sides of the icebergs. Technical details are described in Appendix B, and we focus here on the magnitude of the reflection. Shoreline reflections are observed to decrease with wave height and wave frequency, and strongly increase with bottom slope. Using a nondimensional reflection coefficient $R$ for the wave amplitudes, the energy reflection coefficient is $R^{2}$ [e.g., Mei, 1989]. $R^{2}$ inferred from measurements is less than 0.05 for most wave conditions over a moderately steep beach [Elgar et al., 1994]. Only for nearly vertical cliffs we may expect higher values, up to $R^{2}=0.4$ [O'Reilly et al., 1999] (see also http:// www.coastalresearchcenter.ucsb.edu/cmi/files/2001-055.pdf).

[17] The model distinguishes three types of shorelines. We first define $R^{2}$ for pieces of the shoreline that are longer than the wave model grid spacing (type A: continents and large islands). The shorelines of all smaller islands (type B) are taken from the shoreline database of Wessel and Smith [1996]. For icebergs (type C), $R^{2}$ is again different.

[18] In a compromise between model simplicity and accuracy, we used values of $R^{2}$ that are spatially uniform for each shoreline type, and independent of wave amplitude. Our goal here is not to provide the most accurate modeling of coastal reflection but rather to test a range of plausible values and their impact on seismic noise. We thus obtain $F_{\delta, \mathrm{R}}\left(f_{s}\right)$ with $R^{2}=0.1$ for type $\mathrm{A}, R^{2}=0.2$ for type $\mathrm{B}$, which is fairly arbitrary but intended to give a higher reflection over usually steeper small-scale coral reefs, and $R^{2}=0.4$ for type $\mathrm{C}$ because icebergs have nearly vertical sides. For $R^{2}<$ 0.4 , a double reflection would only give less than $16 \%$ of the incoming energy, which may be neglected. We can thus treat reflection as a linear process and obtain the modeled noise spectra $F_{\delta}\left(f_{s}\right)$ by a linear combination of noise spectra $F_{\delta, \mathrm{R}}\left(f_{s}\right)$ and $F_{\delta, 0}\left(f_{s}\right)$ obtained with and without reflection, respectively. In order to capture some of the observed variability of $R^{2}$ we have chosen a linearly varying frequency dependence given by the empirical function $P$,

$$
P(f)=\max \{0,0.8-5 f / 1 \mathrm{~Hz}\}
$$

so that our estimation of the seismic noise spectrum is

$$
F_{\delta}\left(f_{s}\right)=\left[1-P\left(f_{s} / 2\right)\right] F_{\delta, 0}\left(f_{s}\right)+P\left(f_{s} / 2\right) F_{\delta, \mathrm{R}}\left(f_{s}\right) .
$$

This reflection model gives reflection coefficients in the upper range of those inferred from the beach data of Elgar et al. [1994], with $R^{2}=0.06$ at $f=0.04 \mathrm{~Hz}$ for type A shorelines. An independent validation of $R^{2}$ is provided in the next section.

\section{On the Accuracy of the Wave Model}

[19] Since the work of Gelci et al. [1957], numerical models have been used routinely to estimate and predict the directional wave spectrum $F(f, \theta)=E(f) M(f, \theta)$, and the quality of the frequency spectrum $E(f)$ is relatively well documented [e.g., Rogers et al., 2005; Ardhuin et al., 2007]. The model used here is known to have a slight (10 to 20\%) positive bias for low-frequency energies $f<0.08 \mathrm{~Hz}$ along the U.S. west coast, which is noticeable in a high bias of modeled peak periods [Ardhuin et al., 2010]. The wave model was verified to produce accurate estimations of a wide variety of spectral moments (significant wave height and mean periods). Typical RMS errors for such moments are less than $10 \%$ for 3 -hourly averages, with biases under $5 \%$.

[20] On the contrary, the quality of modeled directional distributions $M(f, \theta)$ is seldom discussed. As a result, the accuracy of seismic noise sources is very uncertain because the $I(f)$ integral (equation (3)) can have very different values with only small changes in the energy for some directions. Although no routine wave measurement can provide an estimation of $I(f)$, we can use other quantities, measured by wave buoys, in order to get some confidence on the quality of modeled $M(f, \theta)$ distributions. We will here examine the first directional moment [e.g., Kuik et al., 1988],

$$
m_{1}(f)=\int_{0}^{2 \pi} M(f, \theta) \cos \left[\theta-\theta_{0}(f)\right] \mathrm{d} \theta,
$$

where $\theta_{0}(f)$ is the mean wave direction at frequency $f$. $m_{1}(f)$ is routinely obtained from heave-pitch-roll buoy data, such as measured by discus-shaped buoys used by the National Data Buoy Center (NBC), and three-axis acceleration data, such as provided by Datawell Waverider buoys, used by the Coastal Data Information Program (CDIP),

$$
m_{1}(f)=\frac{\sqrt{C_{x z}^{2}(f)+C_{y z}^{2}(f)}}{\sqrt{C_{z z}(f)\left[C_{x x}(f)+C_{y y}(f)\right]}}
$$

where $C_{x z}$ is the cospectrum of $x$ and $z$ buoy displacements, with similar notations for the other cospectra. 


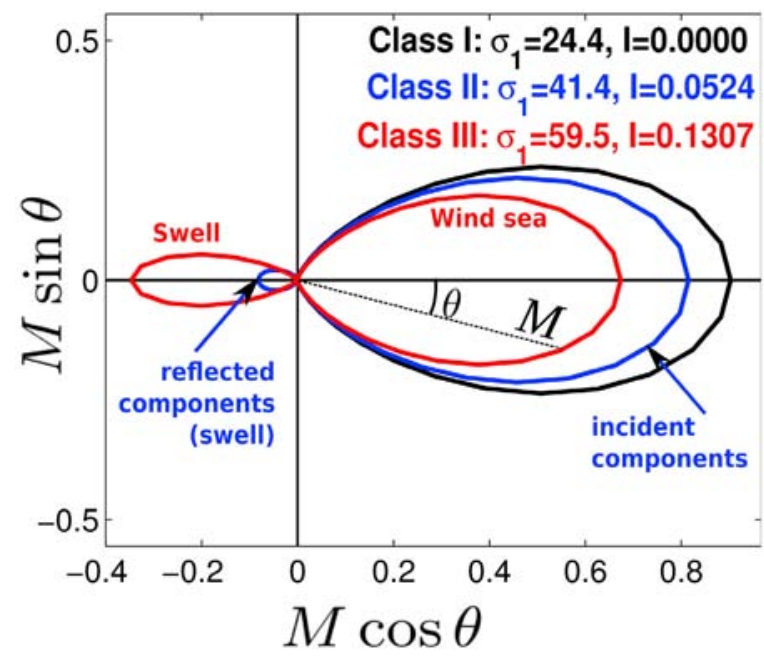

Figure 3. Schematic examples of directional distributions $M\left(f_{0}, \theta\right)$ for a given frequency $f_{0}$ and associated values of $I$ and $\sigma_{1}$. Each color represents as one polar curve the distribution of $M(f, \theta)$ as a function of the angle $\theta$. One example for each class of noise generation is given. Class I corresponds to a single wave system. Here we used $M \propto$ $\cos ^{2 s}(\theta / 2)$ with $s=10$, which, unlike other possible $M$ distributions, is not broad enough to generate a significant noise level. Class II includes coastal reflection, here specular with $R^{2}=0.1$. The class III event chosen here corresponds to a wind-sea of energy $E_{1}$, with $s=10$ against a swell of energy $0.3 E_{1}$ and a narrower directional distribution defined by $s=30 . \sigma_{1}$ is defined by equation (13).

[21] From $m_{1}(f)$ it is customary to define the directional spread as

$$
\sigma_{1}(f)=\sqrt{2\left[1-m_{1}(f)\right]} .
$$

For a directional distribution with a single narrow Gaussian peak, $\sigma_{1}$ is the standard deviation (half-width) of the distribution, and it asymptotes to $88^{\circ}=\sqrt{2} \mathrm{rad}$ as the spectrum broadens to become isotropic. We do not investigate other directional spreading parameters because their estimation from buoy data can be very noisy [O'Reilly et al., 1996].

\subsection{Classification of Noise-Generating Sea States}

[22] For any ocean wave frequency, we can expect three broad classes of sea states for which the directional term $I$ is significant, as illustrated by Figures 2 and 3 .

[23] In class I, the waves generated by the local wind are distributed with some energy at angles larger than $90^{\circ}$ from the mean wave direction, which can then interact with waves in the opposite direction to generate seismic noise. The existence of this oblique energy is well established for wave frequencies typically larger than $0.2 \mathrm{~Hz}$, based on high-frequency radar backscatter from the sea surface [e.g., Wait, 1966]. Hughes [1976] used $I=1 / 16$ for $f>0.5 \mathrm{~Hz}$. Yet, the magnitude of this small amount of energy is very uncertain for wave frequencies below $0.2 \mathrm{~Hz}$, at which most of the seismic noise energy is found.

[24] In class II, reflection from an obstacle (e.g., shoreline, iceberg) provides the source of waves in the opposing direction. Given the usually low reflection coefficient from shorelines, typically $R^{2}<0.05$, the resulting value of $I$ is expected to be less than 0.05 .

[25] Class III corresponds to the much less common situation in which two distinct wave systems have overlapping frequency spectra and opposite directions. One of these systems is usually the wind-sea, forced by the local wind, and the other is a swell, usually propagating from a different generation area. In this case the values of $I$ can be large, possibly more than 0.1 . In the case of turning winds, there is a fuzzy boundary between class I (for rather slowly turning winds) and class III (for more rapidly turning winds) as the wind-sea in the old wind direction turns into swell while a new wind-sea grows in the new wind direction [e.g., van Vledder and Holthuijsen, 1993].

\subsection{Wave Model Accuracy for Class I Situations}

[26] For a single wind-sea system, Donelan et al. [1985] proposed that $M(f, \theta)$ may be distributed like $1 / \cosh ^{2}$ $\left[b\left(\theta-\theta_{0}\right)\right]$, but they acknowledged that there was virtually no information for $\left|\theta-\theta_{0}\right|>90^{\circ}$ and this was further restricted to frequencies less than 1.6 times the peak frequency $f_{p}$.

[27] Banner [1990] used spatial data only, with a $180^{\circ}$ ambiguity on the wave propagation direction, which gives no information at all on the relative values of $M$ in opposing direction. Example of these questionable directional distributions, proposed by Donelan et al. [1985] and Banner [1990], are shown in Figure 4a.

[28] The only wave measurements of good enough quality to provide a reliable estimate of $I$ may be those acquired by Long and Resio [2007]. Their spectra are derived from an array of wave gauges mounted on a surface-piercing support, using the iterative maximum likelihood (IML) method of Pawka [1983], and were averaged for winds varying in a $20^{\circ}$ sector. Some examples of average directional distributions are given in Figure $4 \mathrm{~b}$. The values of $I$ indicated in Figure $4 \mathrm{~b}$ were obtained after removing energy in a $40^{\circ}$ angular sector opposite to the dominant wave direction, in order to remove a potential artifact of the IML estimator, which tends to fill in directional sectors with very little energy, and removes also possible reflections off the instrumentation (C. Long, personal communication, 2010). If the full directional distribution were kept, then the values of $I$ would typically be ten times larger.

[29] The wave model used here gives values of $I$ that, for frequencies in the range 0.1 to $0.3 \mathrm{~Hz}$, i.e., typically $0.5<$ $f / f_{p}<4$, are of the order of 0.003 for a constant wind speed, where $f_{p}$ is the frequency of the ocean wave peak. This value of $I$ is in fair agreement with the directional spectra recorded by Long and Resio [2007] with the exception of the highest frequencies, for which our model is thus likely to underestimate the seismic noise. This is illustrated in Figures $4 \mathrm{c}$ and $4 \mathrm{~d}$ with simple academic calculations with a uniform ocean and a constant $10 \mathrm{~m} / \mathrm{s}$ wind. We find that the model results vary with the wave age, which is the ratio $C_{p} / U_{10}$ of the phase speed at the peak frequency and wind speed $U_{10}$. After $6 \mathrm{~h}$ of simulation $C_{p} / U_{10}=0.6$, and grows to 1.0 after $24 \mathrm{~h}$. The modeled directional distribution is broader for older seas, resulting in larger $I$ values. Other wave model parameterizations typically give smaller values of $I$ by at least 1 order of magnitude (see Appendix C). In real ocean conditions the nonhomogeneity in the wind will naturally enhance $I$ compared to these academic tests, which probably 


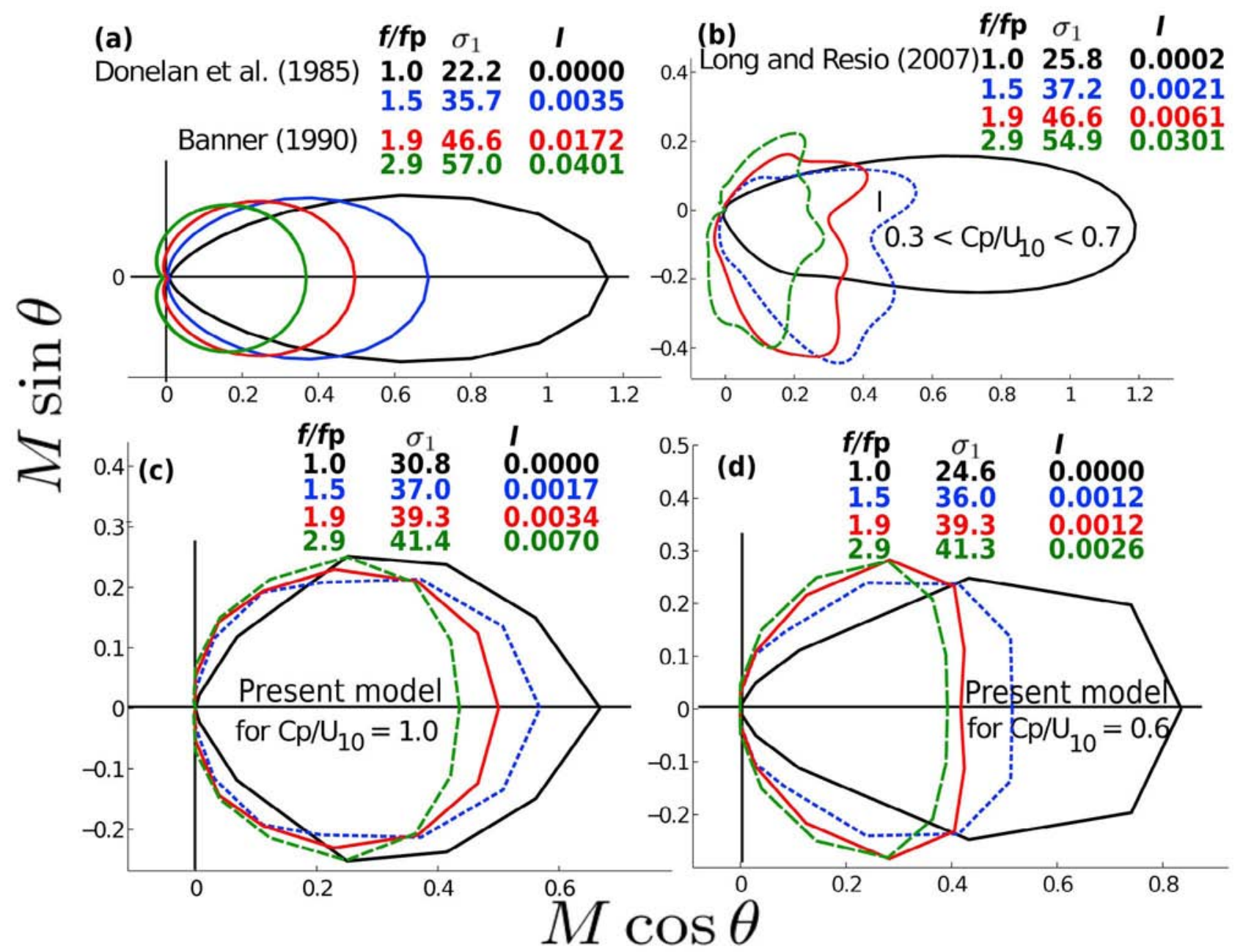

Figure 4. Same as Figure 3, now for class I only based on (a) the directional distributions proposed by Donelan et al. [1985] and Banner [1990], (b) the directional distribution observed by Long and Resio [2007] after removing energy in a $40^{\circ}$ sector opposite to the main direction, and (c, d) using the present model with the $15^{\circ}$ directional discretization used for the model results shown below. In Figure $4 \mathrm{c}$, a mature wind-sea is shown, while Figure $4 \mathrm{~d}$ is a younger wind-sea. The directional distribution $M$ is given by the distance from the origin and is shown for four different frequencies relative to the peak frequency $f_{p}$. In the model, the shape of the directional spectrum is also a function of the wave age, i.e., the ratio of the wave phase speed for the spectral peak, $C_{p}$, and the wind speed at $10 \mathrm{~m}$ height, $U_{10}$.

reduces the differences between models. However, all wave models are most questionable for class I conditions.

\subsection{Wave Model Accuracy for Class II Situations}

[30] For class II, the model accuracy clearly depends on the parameterization of wave reflection. Besides some general knowledge on the decrease of $R^{2}$ with increasing wave heights and mean wave frequencies [Elgar et al., 1994; O'Reilly et al., 1999], there is no published account of how reflection varies with frequency for a given sea state. There is also little knowledge on $R^{2}$ variations with the depth profile of the shore face except for an increase of $R^{2}$ over steeper topographies. There are accurate expressions for the reflections over a random bottom profile for intermediate depths [Ardhuin and Magne, 2007], but these are generally much weaker than the main reflection right at the shoreline. The directional distribution of the reflected wavefield is thus unknown. We have tested reflected distributions of the form $\cos ^{p}\left(\theta-\theta_{r}\right)$ where $\theta_{r}$ is the specular reflection direction and $p$ is a power that we varied from 1 to 4 , and these only changed the magnitude of seismic sources caused by very narrow incident spectrum (typical of swells), by about a factor of two (not shown). It is likely that the model error is mostly defined by the error on the magnitude of $R^{2}$. This magnitude can be validated using directional spreads from buoy data.

[31] For statistical analysis, we use more robust frequencyintegrated moments and spreadings:

$$
\begin{gathered}
M_{1}=\int_{f_{\min }}^{f_{\max }} E(f) m_{1}(f) \mathrm{d} f / \int_{0}^{\infty} E(f) \mathrm{d} f \\
\Sigma_{1}=\sqrt{2\left[1-M_{1}\right]}
\end{gathered}
$$



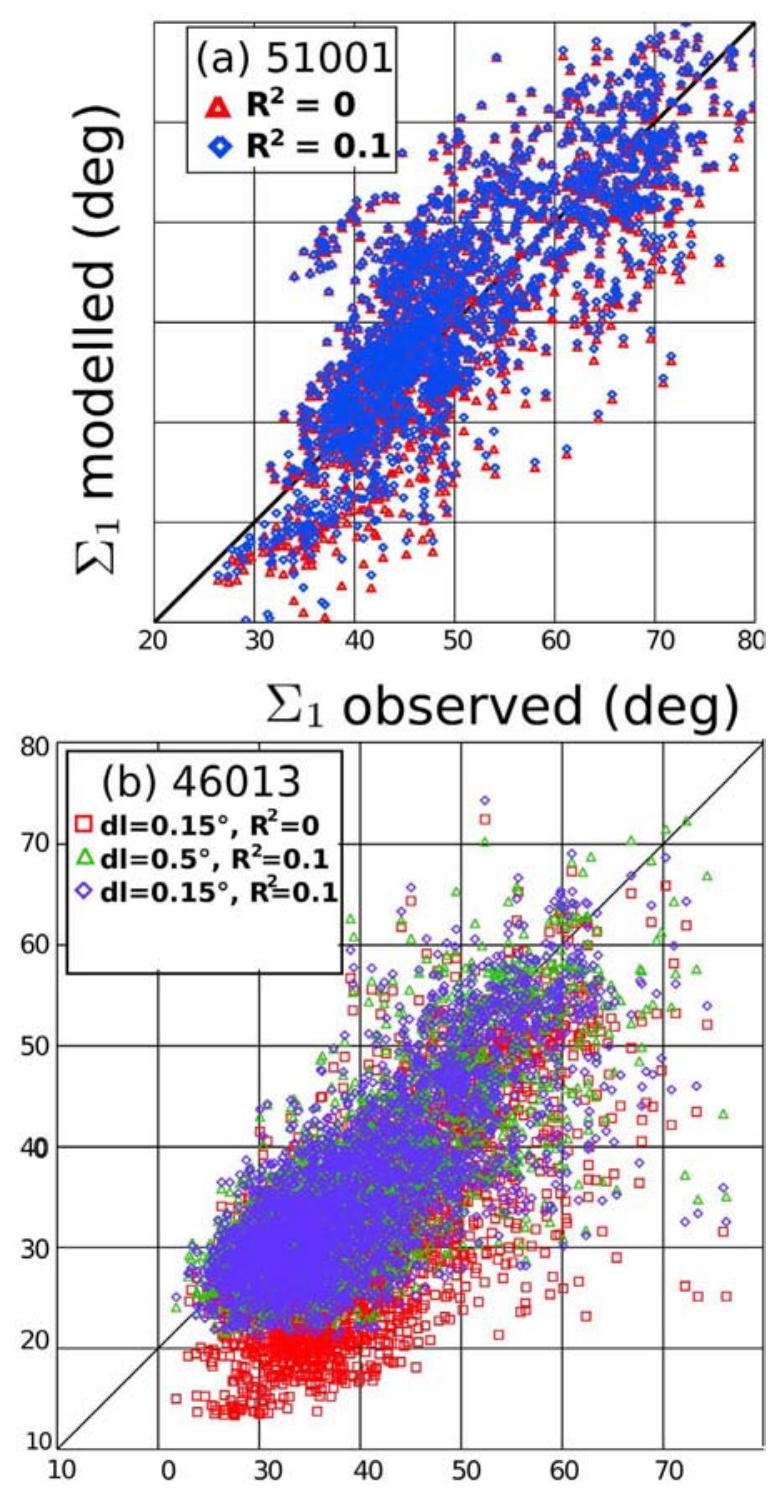

Figure 5. Scatterplot of modeled versus observed directional spread $\Sigma_{1}$, defined by equation (15) (a) for buoy 51001 in 2007 and (b) for buoy 46013 in 2008. For buoy 51001 the model is run with the same resolution $d l=0.5^{\circ}$ and with a constant reflection $R^{2}=0.1$ or no reflection. For buoy 46013 we also test the model with a $1 / 6^{\circ}$ resolution, using a two-way nested zoom into the global $0.5^{\circ}$ grid.

with $f_{\min }=0.04$ and $f_{\max }=0.16 \mathrm{~Hz}$, consistent with our analysis of seismic noise data. At buoy $46214, \Sigma_{1}$ is generally well estimated with $R^{2}=0.1$, together with the other wave parameters. We also verify that the model result with a resolution of $1 / 2^{\circ}$ are very similar to the result with a resolution of $1 / 6^{\circ}$ (Figure 5), even though the buoy is only $1 / 2^{\circ}$ away from land.

[32] The wave model bias for $\Sigma_{1}$ has a strong seasonal cycle, with no bias in summer $(-10 \%$ bias without reflection). In winter the bias without reflection reaches $-30 \%$, and is reduced to $-6 \%$ with a constant $R^{2}=0.1$ applied at all frequencies. This seasonal cycle is correlated to a change in mean wave direction. In summer, dominant waves off this part of the coast are driven by alongshore winds, with a typical direction from $320^{\circ}$ (Figure 6). This alongshore wind-sea is hardly reflected by the shoreline, whereas in winter the dominant wave directions ranges from 280 to 300 .

[33] Still, the model with $R^{2}=0.1$ occasionally overestimates the directional spread in winter. This is the case on 8 January, when $9.6 \mathrm{~m}$ high waves were recorded at buoy 46013 (buoy 46214 did not record this storm due to a power outage) and 24 February with $8 \mathrm{~m}$ waves recorded at 46214 (red star in Figure 6). This is consistent with the observed decrease of $R^{2}$ with wave height [e.g., O'Reilly et al., 1999]. $R^{2}=0.1$ is thus an overestimation for the highest sea states and that part of the coast.

[34] When looking at other locations along the California coastline, $R^{2}=0.1$ typically leads to overestimations of the directional spread (once the buoy bias is corrected for). This is the case, for example, for the $3 \mathrm{~m}$ discus buoy 46042, offshore of Monterey Bay (see Table 1), where most of the shoreline consists of gently sloping beaches.

\subsection{Wave Model Accuracy for Class III Situations}

[35] For class III, the value of $I$ depends on the overlap $\Delta_{\theta}$ of the directional sectors of opposing directions which is determined by the mean direction and directional spreading of the interacting wind-sea and swell systems. These are parameters that can be measured and for which the wave model can be validated. Mean directions exhibit random errors without bias, and these errors will only produce random errors in the noise.

[36] For opposed mean directions $\theta_{1}$ and $\theta_{2}$, positive biases on the directional spreading will generally reduce the noise, because then $M(f, \theta) M(f, \theta+\pi) \Delta_{\theta}$ has lower values since $M(f, \theta) \Delta_{\theta}$ is conserved and $M(f, \theta+\pi)$ is diluted over a wider angular sector. Conversely, as $\theta_{2}$ moves away from $\theta_{1}+\pi$, the noise is zero in the limit of very narrow spectra, and an increase in the spreading can augment considerably the noise level. The directional spreading is thus a key parameter for an accurate noise estimation.

[37] All buoy data were averaged over $3 \mathrm{~h}$ before estimating these parameters. We first consider the $3 \mathrm{~m}$ discusshaped buoy 51001, offshore of Hawaii, representative of open ocean conditions, and a different kind of buoy, a Datawell Waverider, number 46214, located $40 \mathrm{~km}$ from the central California coastline, in $550 \mathrm{~m}$ depth. Basic validation statistics at the two buoys are listed in Table 1, using data for 2008 at 46214 and 2007 at 51001, because directional data is not available for 2008 at that buoy.

[38] Of particular interest are the variations of $\Sigma_{1}$ with and without reflection at the coast. The fact that red and blue symbols in Figure 5a are almost superimposed clearly shows that reflection has little effect on waves recorded at the Hawaii buoy, because that buoy is located $300 \mathrm{~km}$ from small islands.

[39] For $3 \mathrm{~m}$ discus buoy such as 46013, 46042 and 51001 , the estimation of $\sigma_{1}$ is generally noisy and biased high by at least $5^{\circ}$ for which is typically $14 \%$ of the RMS measured value, the same should apply to $\Sigma_{1}$. No bias was found for Datawell waverider buoys such as 46214 [O'Reilly et al., 1996]. Hence our 10 to $15 \%$ bias relative to the 51001 


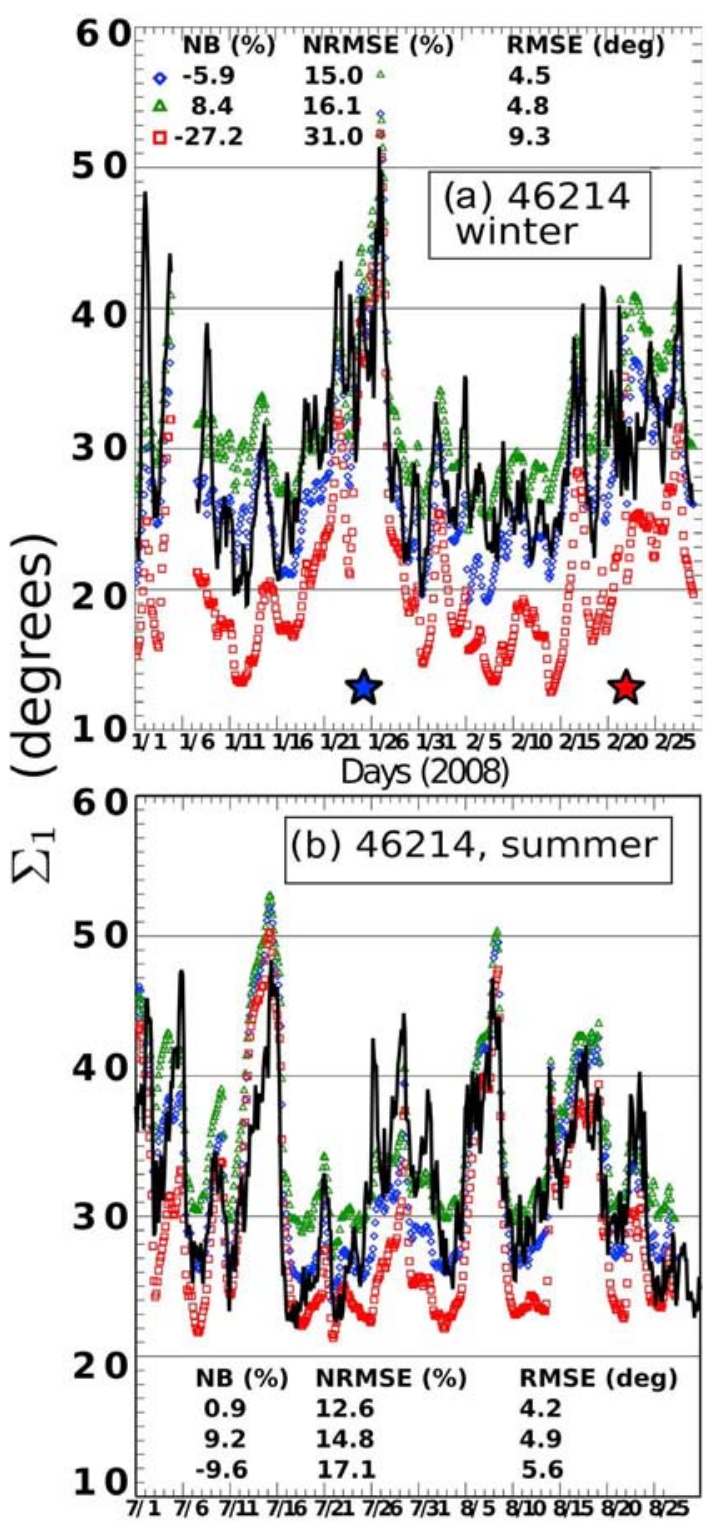

Figure 6. Time series of observed and modeled values of $\Sigma_{1}$ at 46214 for (a) January-February 2008 and (b) JulyAugust 2008. Observations are represented by the solid line. Model runs with a constant reflection $R^{2}=0.1$ are shown in blue and green for the $1 / 6^{\circ}$ and $1 / 2^{\circ}$ resolution, respectively. Red symbols correspond to the $1 / 2^{\circ}$ resolution model without reflection. See Table 1 for a definition of NB, RMSE, and NRMSE.

buoy data probably corresponds to a near-zero bias compared to the real waves.

\section{Spatial Distributions of Seismic Noise Sources}

[40] The above analysis of the wave model performance gives us confidence in the order of magnitude of the estimation of the seismic noise generation given by equation (2). A quantitative validation will be performed below using observed seismic noise. Figure 7 shows the average spatial distribution of modeled seismic sources, in the seismic fre- quency band $0.08-0.32 \mathrm{~Hz}$. In this average, wave-induced pressure fluctuations are largest in the midlatitudes from $40^{\circ}$ to $60^{\circ}$.

[41] More powerful and less frequent storms are needed to make longer-period waves, hence the encounter of two

Table 1. Statistics of Model-Buoy Differences for Various Spectral and Directional Parameters at Buoys $51001(17983 \mathrm{~h}$ Records in 2007), Northwest of Hawaii, and 46013 and 46214, on the Central California Shelf, Located 20 and $40 \mathrm{~km}$ From the Coast, Respectively $^{\mathrm{a}}$

\begin{tabular}{|c|c|c|c|c|c|}
\hline & $H_{s}$ & $H_{s 6}$ & $f_{m 0,-1}$ & $f_{m 0,2}$ & $\Sigma_{1}$ \\
\hline \multicolumn{6}{|c|}{ Buoy 51001} \\
\hline \multicolumn{6}{|c|}{ With constant reflection, $R^{2}=0.1$} \\
\hline NB $(\%)$ & -3.0 & -3.1 & -1.9 & -0.03 & -6.1 \\
\hline SI $(\%)$ & 10.5 & 12.4 & 5.7 & 10.5 & 13.7 \\
\hline RMSE & 0.27 & 0.28 & 0.007 & 0.009 & 6.7 \\
\hline NRMSE (\%) & 10.9 & 12.8 & 6.0 & 5.5 & 15.0 \\
\hline$r$ & 0.95 & 0.95 & 0.95 & 0.95 & 0.75 \\
\hline \multicolumn{6}{|c|}{ Without reflection } \\
\hline NB (\%) & -3.3 & -3.5 & -1.2 & 0.4 & -8.9 \\
\hline SI $(\%)$ & 10.5 & 12.4 & 5.8 & 10.5 & 14.1 \\
\hline RMSE & 0.27 & 0.28 & 0.007 & 0.009 & 7.5 \\
\hline NRMSE (\%) & 11.0 & 12.9 & 5.9 & 5.6 & 16.7 \\
\hline$r$ & 0.95 & 0.95 & 0.95 & 0.95 & 0.74 \\
\hline \multicolumn{6}{|c|}{ Buoy 46214} \\
\hline \multicolumn{6}{|c|}{ With constant reflection, $R^{2}=0.1$} \\
\hline NB $(\%)$ & -5.3 & -5.1 & 0.1 & -4.5 & -5.6 \\
\hline SI $(\%)$ & 12.5 & 14.5 & 6.8 & 9.0 & 13.4 \\
\hline RMSE & 0.38 & 0.38 & 0.008 & 0.016 & 4.7 \\
\hline NRMSE (\%) & 13.6 & 15.3 & 6.8 & 9.9 & 14.5 \\
\hline$r$ & 0.95 & 0.95 & 0.93 & 0.89 & 0.75 \\
\hline \multicolumn{6}{|l|}{ Without reflection } \\
\hline NB (\%) & -6.3 & -6.2 & -0.1 & -4.2 & -19.7 \\
\hline SI $(\%)$ & 12.5 & 14.5 & 6.8 & 9.0 & 15.5 \\
\hline RMSE & 0.39 & 0.40 & 0.008 & 0.015 & 8.1 \\
\hline NRMSE (\%) & 14.0 & 15.8 & 6.8 & 9.9 & 25.1 \\
\hline$r$ & 0.95 & 0.95 & 0.93 & 0.89 & 0.71 \\
\hline \multicolumn{6}{|c|}{ Bиоу 46013} \\
\hline \multicolumn{6}{|c|}{ With constant reflection, $R^{2}=0.1$} \\
\hline NB $(\%)$ & -1.4 & 1.9 & -6.0 & -5.9 & -20.8 \\
\hline SI (\%) & 12.8 & 14.8 & 8.8 & 10.5 & 17.0 \\
\hline RMSE & 0.32 & 0.33 & 0.013 & 0.017 & 10.2 \\
\hline NRMSE (\%) & 12.9 & 14.9 & 10.7 & 10.9 & 26.8 \\
\hline$r$ & 0.95 & 0.95 & 0.92 & 0.89 & 0.61 \\
\hline \multicolumn{6}{|c|}{ Without reflection } \\
\hline NB (\%) & -3.0 & 0.2 & -5.7 & -5.6 & -36.5 \\
\hline SI $(\%)$ & 13.1 & 15.1 & 8.8 & 10.5 & 18.1 \\
\hline RMSE & 0.34 & 0.33 & 0.012 & 0.016 & 15.5 \\
\hline NRMSE (\%) & 13.4 & 15.1 & 10.5 & 10.7 & 40.7 \\
\hline$r$ & 0.95 & 0.95 & 0.92 & 0.89 & 0.56 \\
\hline \multicolumn{6}{|c|}{ Bиоу 46042} \\
\hline \multicolumn{6}{|c|}{ With constant reflection, $R^{2}=0.1$} \\
\hline NB $(\%)$ & -6.0 & -4.2 & -4.2 & -5.6 & -10.3 \\
\hline SI (\%) & 13.6 & 15.1 & 7.9 & 9.5 & 17.1 \\
\hline \multicolumn{6}{|c|}{ Without reflection } \\
\hline NB $(\%)$ & -7.2 & -5.5 & -4.4 & -5.7 & -25.9 \\
\hline SI (\%) & 13.4 & 15.3 & 8.0 & 9.5 & 18.8 \\
\hline
\end{tabular}

${ }^{\mathrm{a}}$ Values are given for the following statistical parameters: bias normalized by the root mean square observed value (NB), scatter index (SI), and Pearson's linear correlation $(r)$. The units for the root mean square error (RMSE) are meters for $H_{s}$, hertz for frequencies, and degrees for $\Sigma_{1}$, and we also give the value of the RMSE normalized by the root mean square observed value (NRMSE). $H_{s 6}$ is the significant wave height defined from the wave spectrum but integrated only up to $f=0.15 \mathrm{~Hz}$, corresponding to the frequency band used here for seismic noise analysis. $f_{m 0,-1}$ is the mean frequency obtained from the spectrum weighted by $f^{-1}$. 


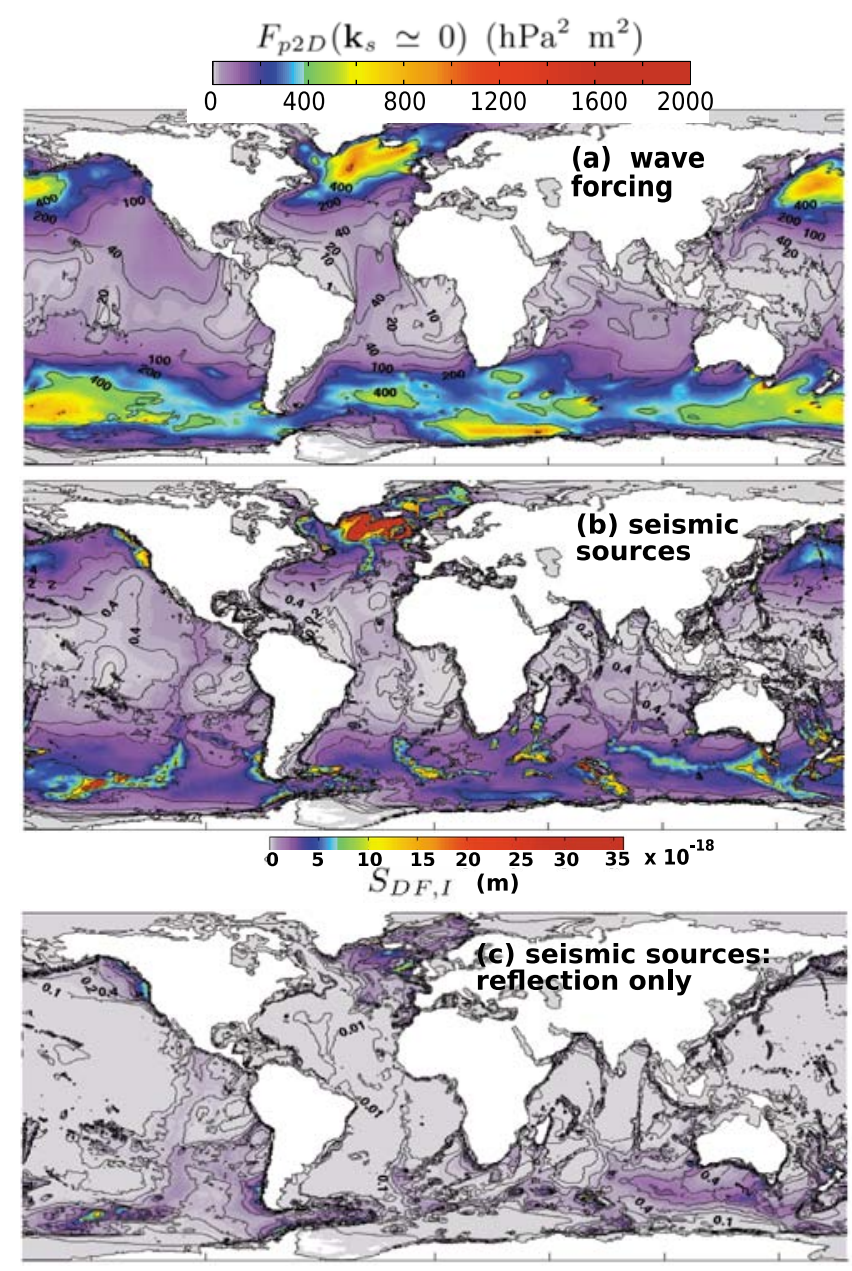

Figure 7. (a) Equivalent wave-induced pressure power spectral density given by the frequency integral of equation (2), $F_{p 2 D}\left(\mathbf{k}_{s} \simeq \mathbf{0}\right)=\int_{0.08 \mathrm{~Hz}}^{0.32 \mathrm{~Hz}} F_{p 3 D}\left(\mathbf{k}_{s}, f_{s}\right) \mathrm{d} f_{s}$, averaged from January to December 2008. (b) Corresponding mean power seismic source that combines the wave forcing shown in Figure $7 \mathrm{a}$ with the amplification due to water depths, as given by equation (5). (c) Same as Figure $7 b$, but showing only the contributions expected from reflections over shorelines and icebergs.

wave trains of frequency $0.05 \mathrm{~Hz}$ from two distinct storms (class III) is a rare source of seismic noise at $f_{s}=0.1 \mathrm{~Hz}$, even though low-frequency swells can propagate to longer distances with minimal energy loss [Ardhuin et al., 2009]. Noise at the lowest frequencies is thus mostly associated with reflections (class II).

[42] As previously noted by Kedar et al. [2008], the water depths on the North Atlantic mid-oceanic ridge correspond to the sharp maximum of $\widetilde{C}$ in equation (5) for average wave periods. Combined with high waves from extratropical cyclones, this feature makes the North Atlantic ridge the most powerful source of seismic noise (Figure 7b). Because the relative importance of coastal reflection is debated, the contribution of reflections, probably overestimated given our choice of reflection coefficients, is isolated in Figure 7c. Reflections significantly increase seismic sources along western coasts, within $1000 \mathrm{~km}$ from shore, in particular in
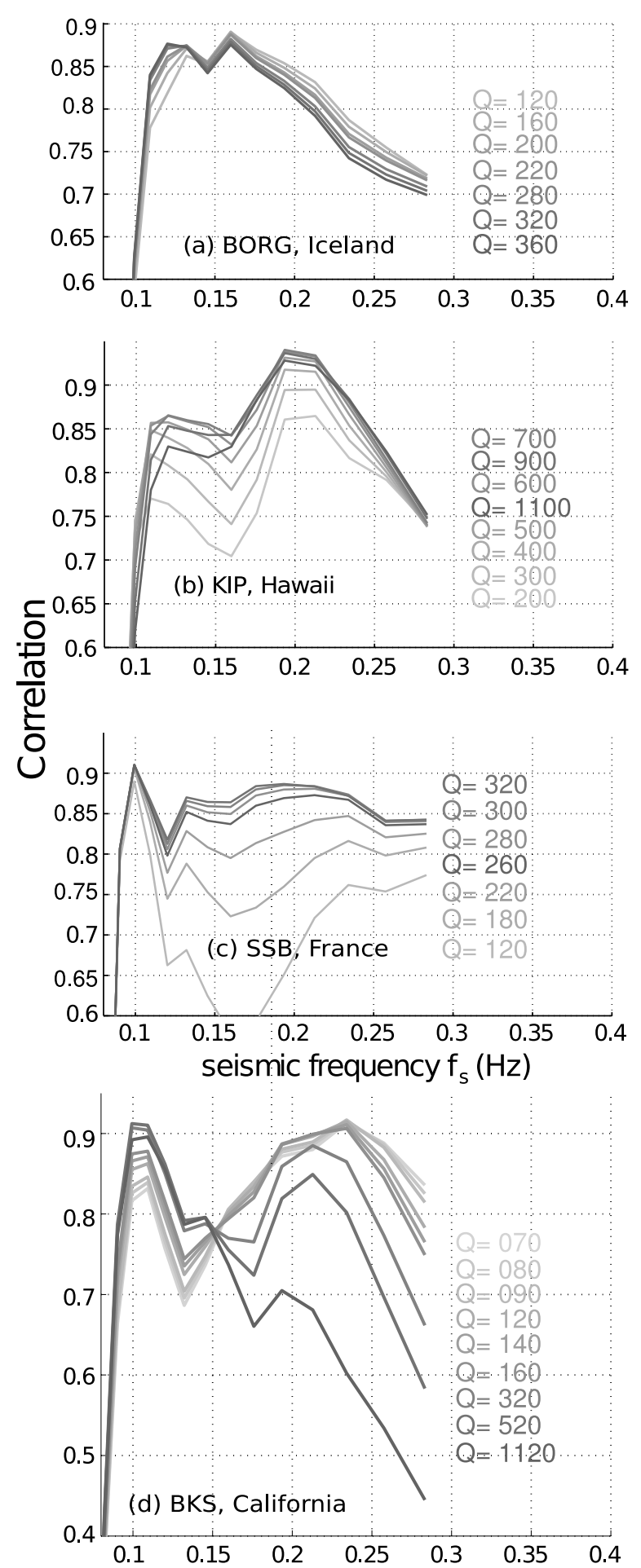

Figure 8. Linear correlation $(r)$ between 3-hourly time series (for the entire year 2008) of modeled seismic displacement for a single frequency band and the corresponding observed time series at (a) BORG, (b) KIP, (c) SSB, and (d) BKS as a function of the quality factor $Q$. Model results use a reflection coefficient $R^{2}(f)$ that decreases linearly from 0.06 at $f=0.04 \mathrm{~Hz}$ to 0.01 at $f=0.15 \mathrm{~Hz}$ for KIP, $\mathrm{SSB}$, and BORG and, for BKS, from 0.1 to 0.015 for the same frequencies. At BKS the two strongest storms (less than $1 \%$ of the time series) were not included in the estimation of correlations. 


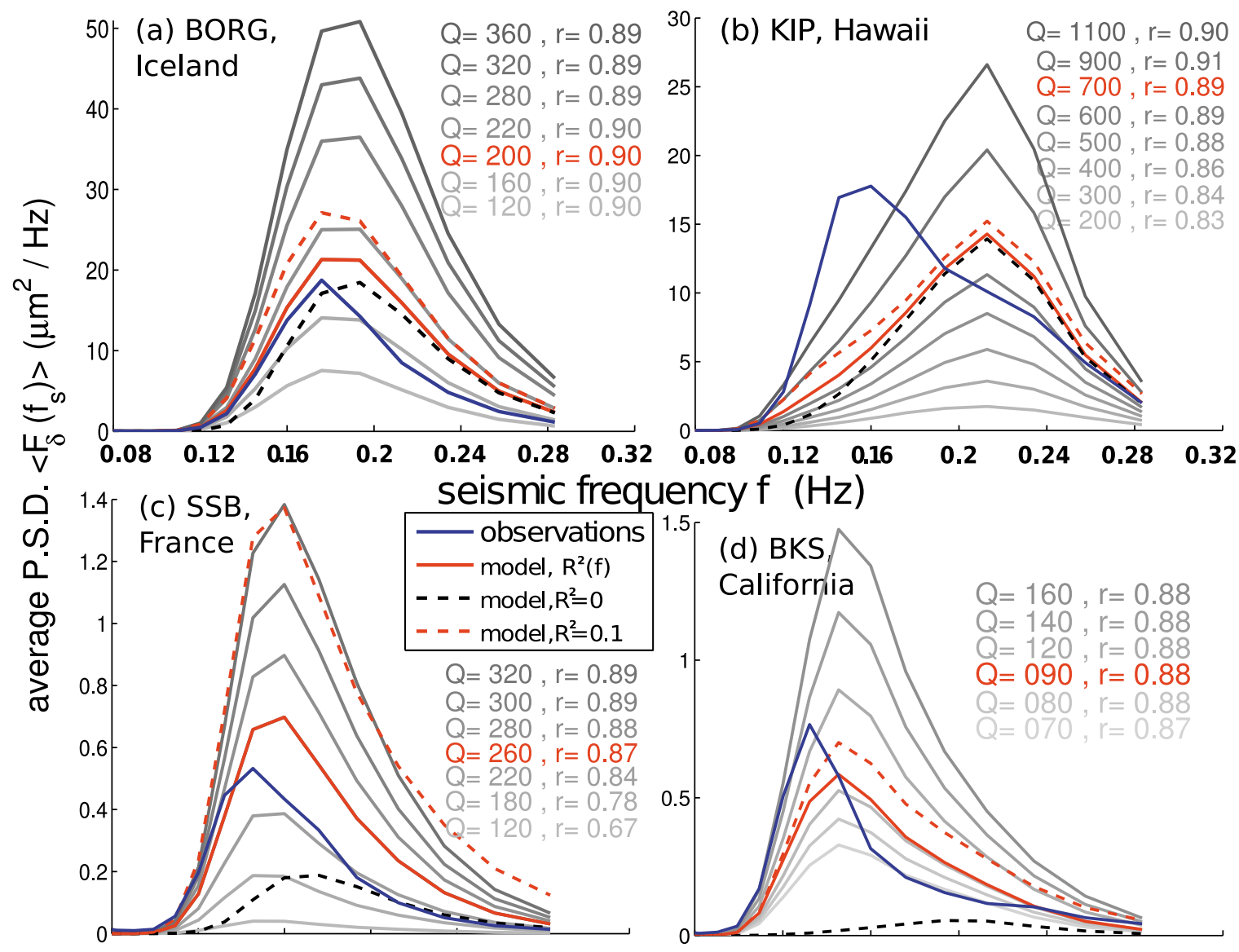

Figure 9. Observed (blue) and modeled (other lines) vertical displacement power spectra at (a) BORG, (b) KIP, (c) SSB, and (d) BKS, averaged over the year 2008. For each station, the sensitivity to a change in $Q$ is illustrated with the shaded lines (we used $U=1.8 \mathrm{~km} / \mathrm{s}$ ). Pearson's linear correlation $r$ between model and observed time series of $\delta_{\text {RMS }}$ are also given. These 3-hourly time series contain of the order of 2400 data points, once earthquakes have been removed. For $Q$ values that provide reasonable spectral levels, the sensitivity to the reflection coefficient $R^{2}$ is illustrated with $R^{2}=0$ (dashed line) and $R_{0}^{2}=$ 0.1 (dashed red line). The reference runs (red line) use $R^{2}(f)$ that decreases linearly from 0.06 at $f=$ $0.04 \mathrm{~Hz}$ to 0.01 at $f=0.15 \mathrm{~Hz}$ for KIP, SSB, and BORG and from 0.1 to 0.015 , for the same frequencies, for BKS. At BKS the two strongest storms (less than $1 \%$ of the time series) were not included in the estimation of $r$.

Europe, from northern California to Alaska, and off the south Chile and south Australia coasts.

[43] In the Southern Ocean, reflections off the Antarctic peninsula, islands, and icebergs are predicted to generate large sources (Figure 7a), in a background of already high seismic generation due to highly variable winds. Although icebergs are particularly numerous in the South Pacific in 2008, compared to other years [Ardhuin et al., 2011], we have not yet been able to isolate their contribution in seismic records due to the large distance between Global Seismic Network stations and the main iceberg concentrations. Iceberg-related sources may be more easily seen in body waves for which the attenuation is weaker. We now verify and discuss the other model predictions.

\section{From Sources to Seismic Stations}

[44] The seismic attenuation, given by the product $U Q$, defines the horizon of sources observable by a given station.
For a given frequency, $U Q$ changes with crust properties, with strong variations between oceanic and continental crusts [e.g., Mitchell, 1995; Mooney et al., 1998; Savage et al., 2010]. UQ also varies with frequency [Dziewonski and Anderson, 1981].

[45] In the following, we chose a constant but realistic $U=1.8 \mathrm{~km} \mathrm{~s}^{-1}$. For $Q=605(Q=151)$, seismic energy at $f_{s}=0.15 \mathrm{~Hz}$ is halved during propagation every $800 \mathrm{~km}$ $(200 \mathrm{~km})$.

[46] We adjust $Q$ separately for each seismic station to set the value of $U Q$. This approach allows us to account for some of the spatial variability of $Q$, but it should only make sense for stations to which noise has traveled across relatively uniform crust. Faced with the limited knowledge of $U Q$ in the main seismic noise frequency band, values of $Q$ for the model were selected with the objective to reproduce the temporal variability of the seismic noise, maximizing the linear correlation $r$ (Figure 8), while keeping realistic noise 

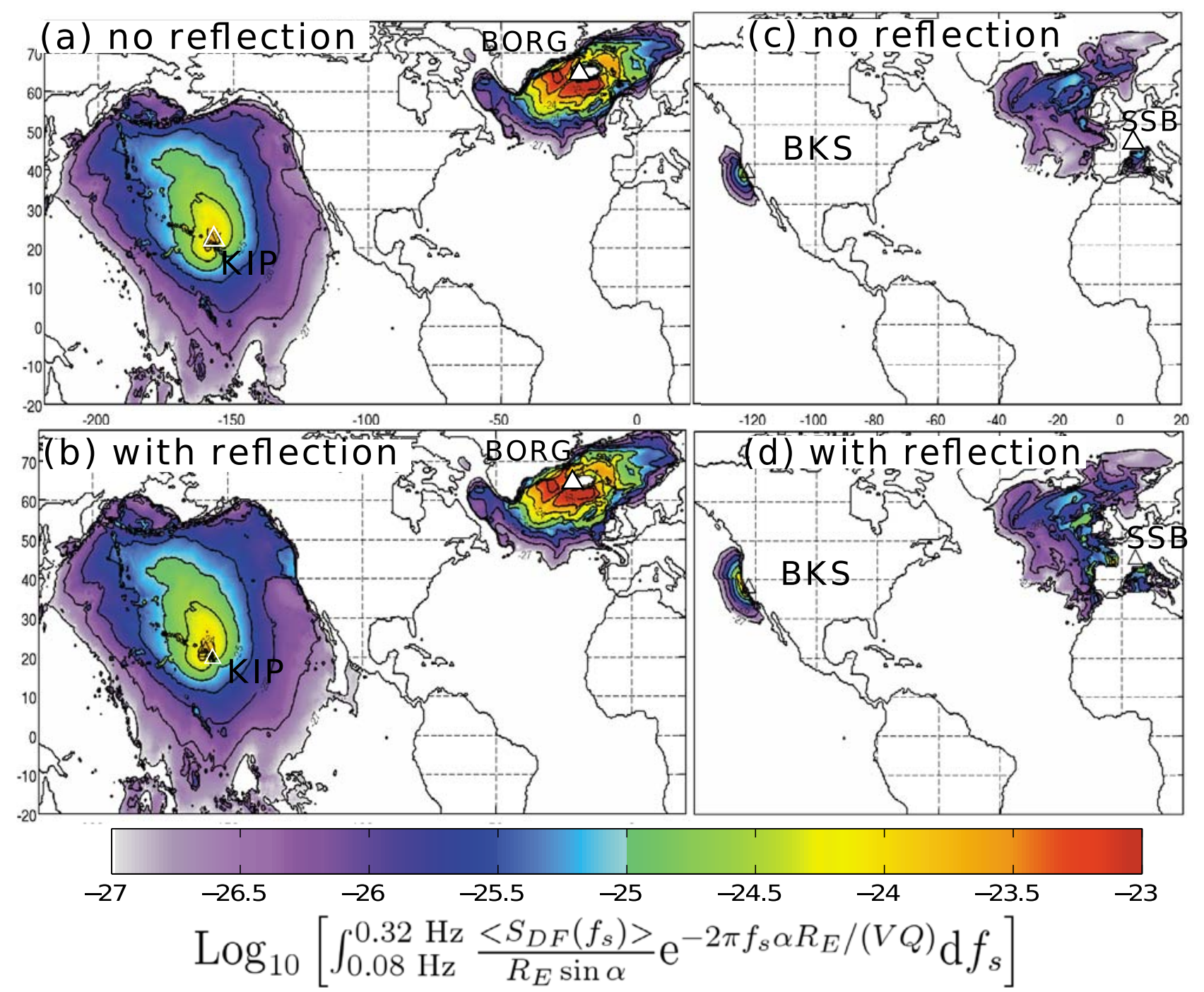

Figure 10. Distribution of sources recorded at various stations, averaged over the year 2008. Station locations are indicated by triangles. (a, b) Sources seen by seismic stations KIP and BORG. (c, d) BKS and SSB. The color shades correspond to the average of the integrand in equation (6), now integrated over the frequency band $0.08-0.32 \mathrm{~Hz}$, which is a dimensionless quantity, in logarithmic scale. A value of -23 uniform over a square of sources with a side of $300 \mathrm{~km}$ gives a displacement variance $\delta_{\mathrm{RMS}}^{2}=1 \mu \mathrm{m}^{2}$ at the station, for that square alone. $Q$ values used here are 580,180, 260, and 88 for KIP, BORG, SSB, and BKS, respectively. Figures 10a and 10c are estimated without any wave reflection, whereas Figures $10 \mathrm{~b}$ and $10 \mathrm{~d}$ are estimated with reflection. For BKS the shoreline reflections are increased by $50 \%$.

levels (Figure 9). Here $r$ is Pearson's linear correlation coefficient defined as

$$
r=\frac{\sum_{i=1}^{N}\left(X_{i}-\bar{X}\right)\left(Y_{i}-\bar{Y}\right)}{\sqrt{\left(\sum_{i=1}^{N}\left(X_{i}-\bar{X}\right)^{2}\right)\left(\sum_{i=1}^{N}\left(Y_{i}-\bar{Y}\right)^{2}\right)}},
$$

where the overbar denotes the arithmetic average, i.e., $\bar{X}=$ $\left(\sum_{i=1}^{N} X_{i}\right) / N$, and $X$ and $Y$ are series of the two quantities considered. Here $X$ and $Y$ are the observed and modeled spectral densities at a given frequency.

[47] For high $Q \mathrm{~s}$, seismic sources from a vast area of the ocean contribute to the seismic record, while a low $Q$ means that sources are concentrated in the vicinity of the seismic station. Since dominant ocean waves generally have a strong variability at scales larger than $300 \mathrm{~km}$ [e.g., Tournadre, 1993] we expect a similar variability in noise sources given by the model. When sources are widely distributed over distances from a seismic station, there should only be a limited range of $Q$ values that will put the proper weight on nearby and remote stations and yield realistic noise time series.

[48] After calibrating the wave model, $Q$ factors, and frequency dependence of $R^{2}$ for the year 2007, we illustrate the model validation with data from the year 2008, with four seismic stations: KIP (Hawaii), BORG (Iceland), BKS (central California) and SSB (France). This choice was motivated by the desire to span a wide range of seismic noise climates, from noisy island stations (KIP and BORG) 

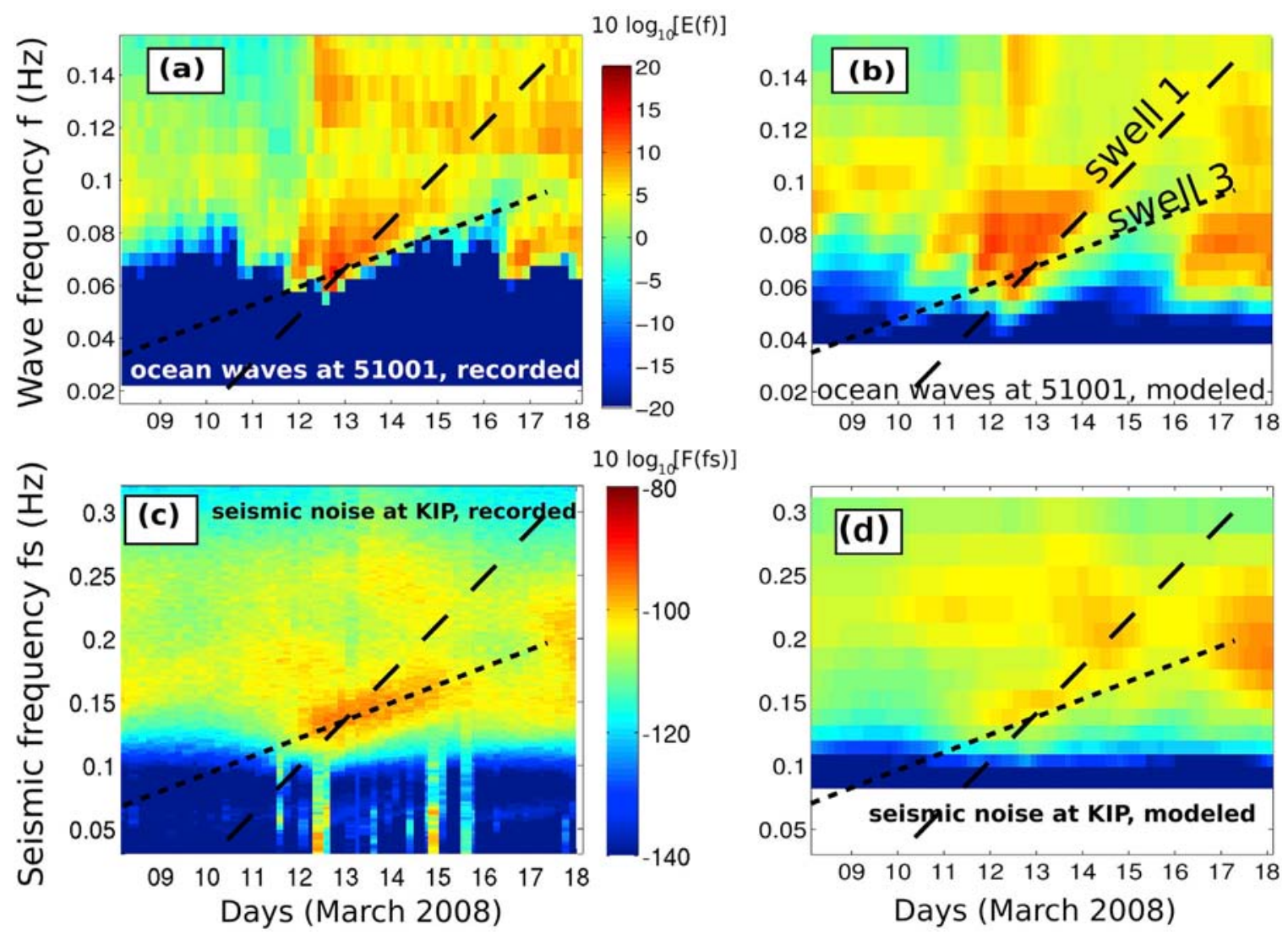

Figure 11. (a) Observed and (b) modeled wave frequency spectra $E(f)$ at the location of buoy 51001 to the northwest of Hawaii for a few days in March. (c) Observed and (d) modeled seismic noise at the KIP station for the same time frame and the corresponding double frequencies. The dashed lines are the same in all four figures and outline the dispersive arrival of two swell systems, one from the northwest with a steeper slope due to a closer source and one from the southwest with a weaker slope. The two lines cross around 0300 UTC on 13 March 2008.

to calmer mainland stations further (SSB) or closer (BKS) to shore. We have also tested the model at many other locations with a similar degree of performance except for Dumont d'Urville (DRV), where the wave model performance near the sea ice edge may be an issue, and Mexico City (UNM) where high-frequency noise $\left(f_{s}>0.2 \mathrm{~Hz}\right)$ is not well reproduced, possibly due to seismic amplification associated with the local sedimentary basin. (These locations include the seismic stations CMLA (Azores), ESK (Scotland), EFI (East Falkland Islands), SCZ (Salinas, California), JTS (Costa Rica), RPN (Easter Island), NNA (Nana, Peru), COR (Corvallis, Oregon), RER (Reunion Island), PPT (Papeete, French Polynesia), INU (Inuye, Japan), FDF (Fort de France, Martinique), KDAK (Kodiak Island, Alaska).)

[49] Seismic spectra are obtained from the LH channel (1 sample per second) of broadband STS1 or STS2 seismometers. In the frequency of interest there are negligible differences between the two instruments. Seismic displacement spectra were computed with overlapping windows, instrumental responses were removed, and spectra were averaged over $4 \mathrm{~h}$ segments [e.g., Stutzmann et al., 2000], giving 28 degrees of freedom for each spectral estimate at a spectral resolution of $0.001 \mathrm{~Hz}$.
[50] Because ocean wave properties change only on a time scale of a few hours, segments with earthquakes or instrument glitches were filtered out as follows. Using the lowfrequency ground displacement variance $E_{l f}$ (in the band 0.05-0.1 Hz where wave effects should be minimal), records were discarded when $E_{l f}$ jumped by a factor 8 over $4 \mathrm{~h}$, provided that $E_{l f}$ was larger than a station-dependent threshold. This threshold was set to $3 \times 10^{-12} \mathrm{~m}^{2}$ for BORG, $1 \times 10^{-13} \mathrm{~m}^{2}$ for KIP, $1 \times 10^{-15} \mathrm{~m}^{2}$ for SSB, and $1 \times 10^{-14} \mathrm{~m}^{2}$ for BKS. After this step, seismic spectra were interpolated in time on the $3 \mathrm{~h}$ time step of the wave model output.

[51] Spectral levels from all four stations (Figure 9) suggest that $Q$ should decrease from about $200-1000$ at $f_{s}=0.12 \mathrm{~Hz}$, to about $50-300$ at $f_{s}=0.3 \mathrm{~Hz}$, consistent with previous estimations [Mitchell, 1995]. A reasonable correlation and spectral level is obtained at seismic stations KIP, BORG, BKS, and SSB using 580, 180, 260, and 88 for $Q$, respectively. Since we have neglected the three-dimensional seismic propagation effects that can reduce appreciably the energy level at the seismic station, these effects are partially compensated by artificially lower values for $Q$. Any bias in the numerical wave model may similarly be compensated. Still this variation of $Q$ is generally consistent with results at longer periods by Mitchell [1995], who showed that $Q$ is generally higher for older crust, as found around Hawaii, 
and lower for younger crust, as found offshore of California. A systematic investigation of the variability of $Q$ with frequency and location will be performed in another paper.

[52] Because $Q$ varies spatially, sources contribute differently to different seismic stations. Figure 10 shows the
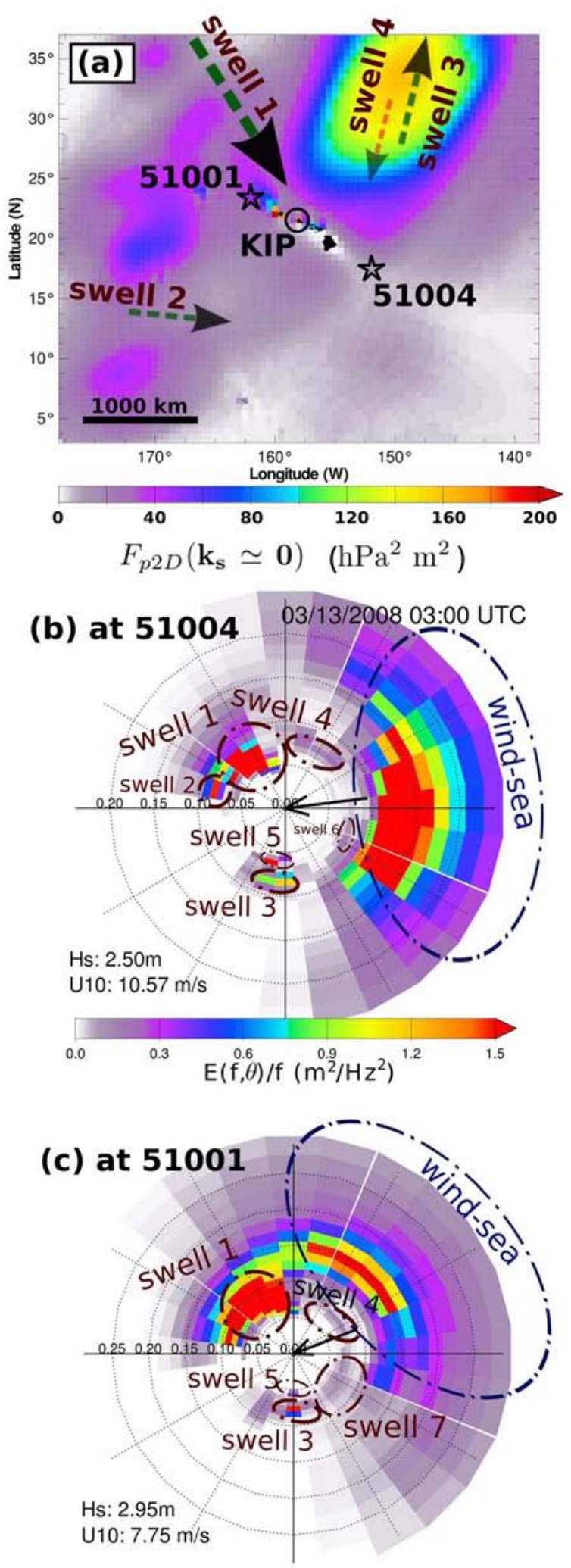

average expected source distributions for the four chosen stations. We shall now discuss each station specifically.

\subsection{Where Reflection Is Usually Negligible}

[53] Our tour begins with BORG and KIP, where shoreline reflection makes little contribution, as shown by the small difference between the solid red and dashed black curves in Figure 9. Increasing further the shoreline reflection coefficient to unrealistically high values will not change this result. In the case of KIP, reflection is negligible because the Hawaiian islands are very small compared to the area of the noise sources. On some occasions the effect of reflections can be seen, in particular for the lowest frequencies, but the resulting noise is often too weak to dominate other sources. Figure 11 shows one example of observed and modeled wave spectra at the wave buoy number 51001 which is the closest to the KIP station, and the recorded and modeled seismic noise at KIP. Contrary to coastal data from central California coast [e.g., Bromirski et al., 1999], there is little resemblance between the wave and seismic spectra which are both fairly well represented by the model. Although they are blurred in the seismic record, one can still track the same swell events in both seismic and wave records.

[54] Focusing on 13 March 2008 at 0300 UTC, the modeled noise map (Figure 12a) can be explained by a careful examination of the directional wave spectra around Hawaii (Figures 12b and 12c). The broad region of relatively strong seismic sources to the northeast of Hawaii has a seismic peak period of $7 \mathrm{~s}$, corresponding to $14 \mathrm{~s}$ waves. The wind-sea at that time is unable to contribute to these frequencies but, in the modeled spectrum at the location of the southeast buoy 51004, there are four swell systems that could contribute to this noise. Only swells number 3 and 4 have opposite directions. At the location of buoy 51001 there is one more swell system, number 7 , generated by the reflection of swell 1 off the islands (it is absent in the model run without reflection).

[55] Swells 1 and 7 do interact to produce some noise but this source has a very limited spatial extension, about 300 by $800 \mathrm{~km}$ in the vicinity of the westernmost island. Swell 1 was generated by a northwest Pacific storm on 9 March $3500 \mathrm{~km}$ away from Hawaii, consistent with the slope of the long-dashed lines in Figure 11. This same storm was not a very strong source of noise by itself, with modeled values of $F_{p 2 D}\left(\mathbf{k}_{\mathbf{s}} \simeq \mathbf{0}\right)$ under $200 \mathrm{hPa}^{2} \mathrm{~m}^{2}$.

Figure 12. (a) Map of modeled frequency-integrated wave-induced pressure spectral density $F_{p 2 D}\left(\mathbf{k}_{\mathrm{s}} \simeq \mathbf{0}\right)$ (shown in colors) over the seismic frequency band $0.1-0.2 \mathrm{~Hz}$ on 13 March 2008 at 0300 UTC, around Hawaii, also showing the positions of the Kipapa seismic station (KIP) and two ocean buoys of the National Data Buoy Center. Arrows indicate the propagation directions of swell systems present, with the size of the arrow giving an indication of the swell height. The plotted shoreline from Wessel and Smith [1996] was used to define the subgrid shoreline blocking and reflection. Only the Big Island is directly resolved by the model (two grid points), and all the other islands are treated as subgrid obstacles. (b, c) Modeled polar wave spectrum $E(f, \theta) / f$ at buoys 51001 and 51004 . 


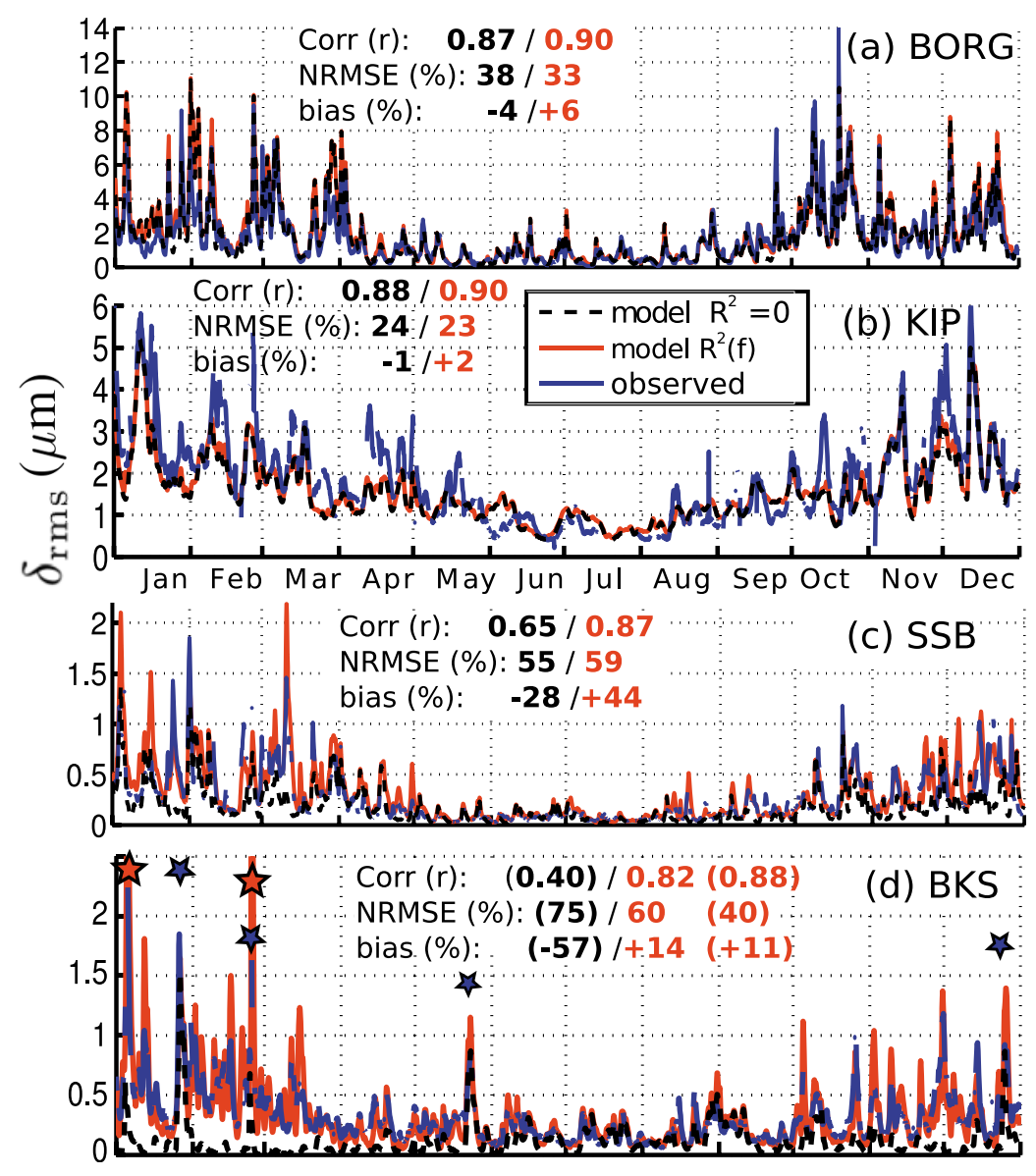

Figure 13. Observed and modeled RMS vertical ground displacement at stations (a) BORG, (b) KIP, (c) SSB, and (d) BKS over the year 2008. The statistics given in each plot quantify the model observation differences, in red for the full model and in black for the model without reflection. These are Pearson's linear correlation coefficient $(r)$, the root mean square error normalized by the root mean square observed value (NRMSE), and the bias normalized by the root mean square observed value. The downward pointing blue stars in the BKS time series mark the times of the largest modeled peaks without reflection, including the 26 January event. The two upward pointing red stars correspond to situations where the model largely overpredicts the observed levels (these two peaks have been clipped). Statistics excluding these two events (less than $1 \%$ of the time series) are given in parentheses.

[56] According to the model, the strongest source of noise on 9 and 10 March was a Gulf of Alaska storm which peaked at $10000 \mathrm{hPa}^{2} \mathrm{~m}^{2}$ on 9 March, and sent waves to the northeast, crashing on the Alaskan shoreline, with very little swell radiated in the Pacific. This other storm was joined by a deep extratropical depression that moved very fast to the east, from $40 \mathrm{~N} 150 \mathrm{~W}$ on 9 March at $1200 \mathrm{UTC}$ to $51 \mathrm{~N}$ $135 \mathrm{~W}$ by 11 March at 0000 UTC. This storm is the source of swell number 4. As for swell number 3, it was generated on 3 March in a Southern Ocean storm located near $59 \mathrm{~S}$ $158 \mathrm{~W}, 10000 \mathrm{~km}$ away from Hawaii, which is consistent with the dotted line in Figure 11. This swell 3 is much weakened when arriving around Hawaii, yet it meets swell 4 in the exact opposite direction. These two swells give the largest noise source recorded at KIP station in Hawaii on 16-20 March, although they only give a very small contribution to the wave energy recorded at the 51001 wave buoy.

[57] With $R^{2}$ irrelevant for KIP, $Q$ remains the only tunable parameter in the model, and model-data correlations are very sensitive to it (Figure 9b). This sensitivity is con- sistent with the fact that modeled sources span a wide range of distances from KIP (Figure 10). The high values of $Q$ needed to fit the observed noise reveals that KIP effectively integrates sources from a very large area in the North Pacific, which explains the smoother appearance of the KIP time series (Figure 13b) compared to other stations. We finally note that the highest correlations are given by $Q \simeq 1000$, which would produce too high spectral levels for $f_{s}>0.15 \mathrm{~Hz}$. Adding a frequency-dependent refraction term $N$ in equation (6) decreasing with $N \simeq 1$ at $f_{s}=0.15 \mathrm{~Hz}$ and $N<0.4$ at $f_{s}=0.15 \mathrm{~Hz}$, would produce a more accurate empirical model.

[58] At BORG in Iceland, a lower $Q$, compared to KIP, with stronger North Atlantic sources, compared to the North Pacific, yields the observed similar noise levels (Figures 9a and $9 \mathrm{~b}$ ). Varying $Q$ at BORG makes little change to modeldata correlations for each frequency (Figure 8) and globally for $\delta_{\mathrm{RMS}}(0.87<r<0.90)$, but it dramatically impacts the noise level (Figure 9a). This insensitivity of $r$ in the model results from the fact that contributing sources are at the same 


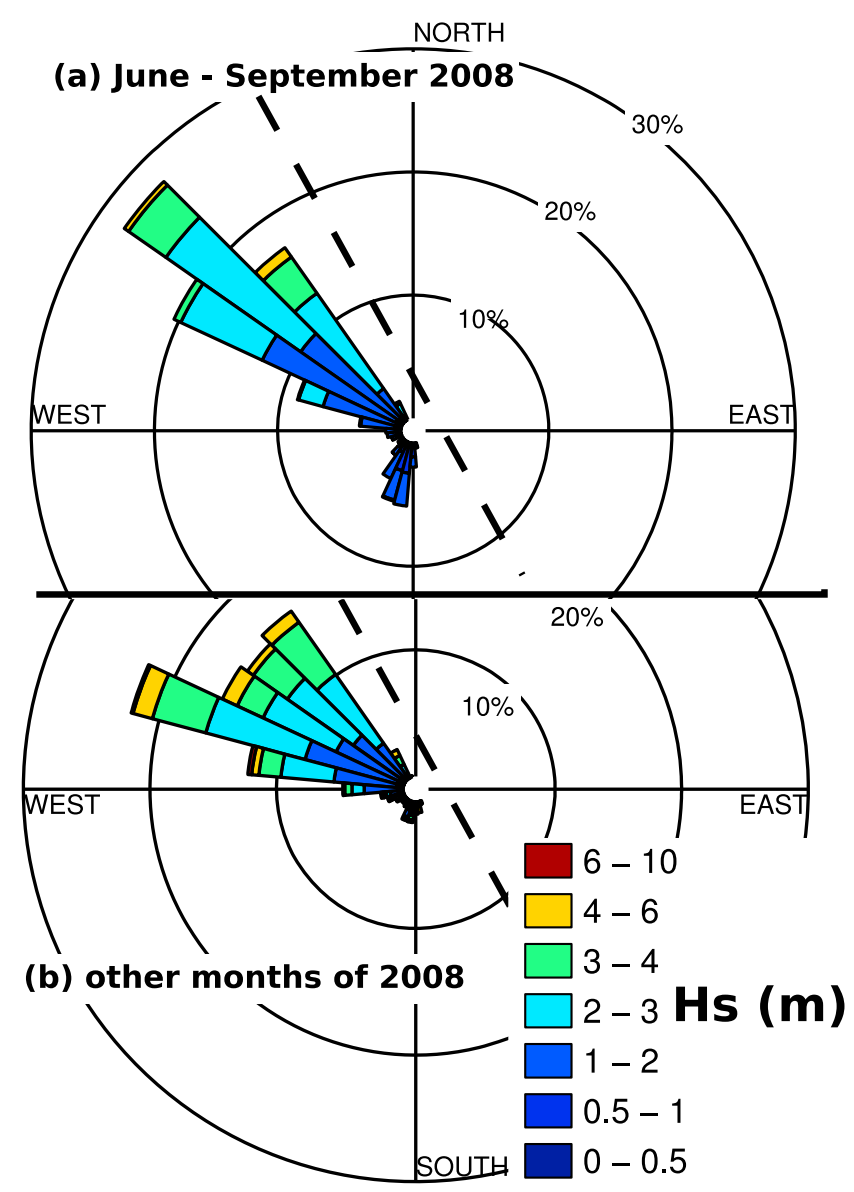

Figure 14. Distribution of wave heights and mean wave directions (from) at the peak frequency observed at the 46013 buoy, located off central California, in the year 2008 for (a) summer months and (b) the rest of the year. The mean shoreline direction is indicated by the dashed line.

distance from BORG, in a small section of the mid-Atlantic ridge (Figure 10a), to the southwest of Iceland. The model appears to reproduce as well the strong noise events, with $\delta_{\text {RMS }}$ up to $14 \mu \mathrm{m}$ for durations less than a day, and the low noise background with $\delta_{\mathrm{RMS}}$ under $2 \mu \mathrm{m}$. In this respect the present model appears more accurate than the previous noise model by Kedar et al. [2008, Figure 6].

\subsection{Where Reflection Is Important or Dominant}

[59] The French SSB station is representative of western Europe, with an intermediate noise climate. There, model results are highly sensitive to both $Q$ and $R$. A uniform $Q=$ 260 gives acceptable correlations (Figure 13c), with powerful mid-Atlantic sources and closer coastal sources contributing equally. As in Hawaii, the correlation can be improved by increasing $Q$, here up to 320 , but this produces noise levels that are a factor of two too high for $f_{s}>0.15 \mathrm{~Hz}$. Here again, seismic wave refraction is a likely omitted factor. The model adjustment is also complicated by the important role of coastal reflection, which is only poorly approximated by a spatially uniform reflection coefficient $R^{2}$.

[60] Our journey ends in central California where, like at other stations [e.g., Stutzmann et al., 2000, 2009], lower frequencies dominate in winter, with here a peak at $f_{s}=0.13 \mathrm{~Hz}$, while summer energetic signals are above $f_{s}=0.16 \mathrm{~Hz}$. After comparing the synthetic noise spectra to seismic data from BKS, and based on directional measurements at nearby buoys (section 3 ), we increased $R^{2}$ by $50 \%$, relative to all other model calculations. Values of the seismic ground displacement $\delta_{\mathrm{RMS}}$ estimated for BKS are as high as 4.2 and $5.4 \mu \mathrm{m}$ in January and February 2008, compared to maximum recorded values of 2.2 and $1.6 \mu \mathrm{m}$ only (red stars in Figure 13d). These overestimations occur for the two strongest storms of 2008, with ocean wave heights of 9.5 and $7 \mathrm{~m}$ measured at the 46013 buoy, while wave heights are less that $6 \mathrm{~m}$ for the rest of the year. Clearly our shoreline reflection coefficient $R^{2}(f)$ is overestimated for these two events. The buoy data (Figure 14a) and the seismic noise model (Figure 13d) suggests that $R^{2}$ should decrease with wave height, as expected [Elgar et al., 1994; O'Reilly et al., 1999].

[61] We also note that any constant $Q$ leads to a poor shape of the synthetic noise spectrum (Figure 9d). In fact, for $f_{s}<0.15 \mathrm{~Hz}$ (dominant in winter) the time series of synthetic noise levels are well correlated with the BKS records for a very wide range of $Q \mathrm{~s}$, from 70 to 520 , whereas the higher frequencies require a lower $Q$, in the range $60-160$, to produce any decent correlation (Figure 8d). These two frequency domains may correspond to different seismic modes [Haubrich and McCamy, 1969], but they also correspond to different classes of seismic generation events. Indeed, according to the model, reflection only plays a minor role in summer (the dashed and red lines are almost identical for June to September in Figure 13d), and class III is relatively rare, thus the summer noise is mostly produced by class I events with $f_{s}>0.15 \mathrm{~Hz}$. This is easily understood from the wind directions which blows alongshore in summer and thus generates waves that mostly propagate alongshore (Figure 6a) with very little coastal reflection. Swells from the southwest, that are also present in summer, do not apparently contribute much to the noise recorded at BKS, contrary to southern California stations such as Pasadena (not shown).

[62] In winter the wind and wave directions have typical directions that differ from summer wave directions by $20^{\circ}-$ $30^{\circ}$ (Figure 6b), hence resulting in stronger reflected wave components. Because the modeled noise without reflection is often near zero, we can conclude that class II dominates in winter.

[63] For the lower frequencies, the large winter storms hit the U.S. west coast rather uniformly, creating strong noise sources offshore of northern California and Oregon. It is possible that seismic attenuation is weak, with $Q \simeq 500$, and that the seismic energy that reaches BKS is strongly reduced by refraction (by about a factor 10). In this case, BKS records could be influenced by sources as far as the Oregon shelf edge. It is also possible that the noise is mostly coming from central California waters, i.e., $Q \simeq 100$ and that refraction does not play an important role. For the higher frequencies $\left(f_{s}>0.15 \mathrm{~Hz}\right)$ the sources must be fairly local, within $300 \mathrm{~km}$, because increasing $Q$ to 320 already degrades the correlations between modeled and recorded noise level time series.

[64] Even in winter, some strong noise events are unrelated to reflections and correspond to class III events (blue 


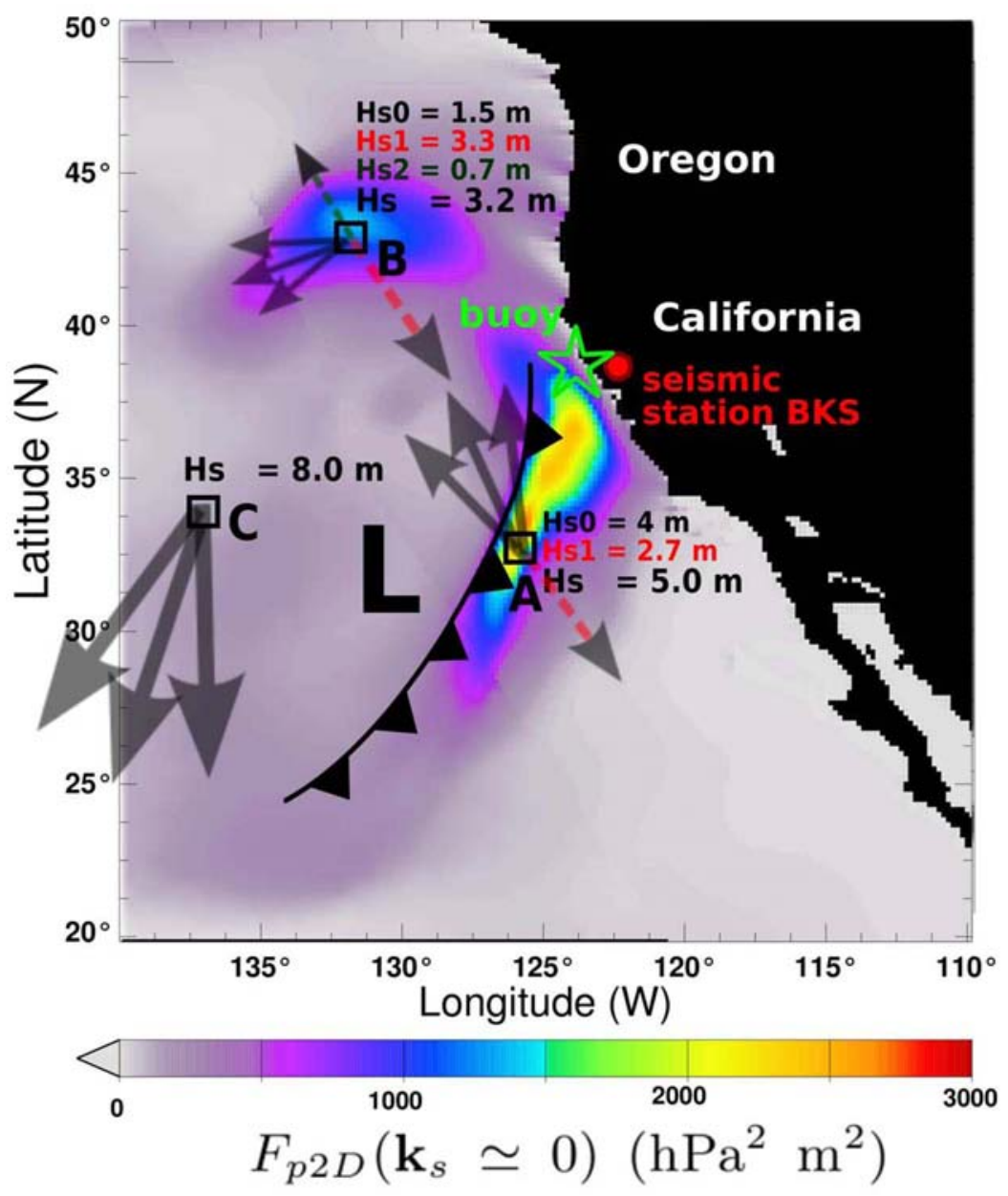

Figure 15. Map of modeled frequency-integrated wave-induced pressure spectral density (shown in colors) for the complex weather situation of 26 January 2008 at 1200 UTC, which combines heavy swells from the northwest and a low atmospheric pressure (L) centered at $32^{\circ} \mathrm{N}, 132^{\circ} \mathrm{W}$, with an associated cold front (line with triangles) where the wind changes rapidly from strong southerlies to weak winds. Wave parameters are represented schematically at three locations (squares), including the wind-sea (groups of three arrows, and heights given by $H_{s 0}$ ), and swells, when they are present (dashed arrows and heights $H_{s 1}$ and $\left.H_{s 2}\right)$.

stars in Figure 13d). For such an event, on 26 January 2008, $\delta_{\mathrm{RMS}}$ reached $1.8 \mu \mathrm{m}$ (Figure $13 \mathrm{~d}$ ), the second largest recorded value for 2008 . The modeled wave-induced pressure for that event is shown in Figure 15.

[65] A low pressure offshore of California produced winds over $25 \mathrm{~m} / \mathrm{s}$ which, to the west, amplified swells from the northwest (generated by another storm off Washington State) into high seas ( $H_{s}$ up to $8 \mathrm{~m}$ at point $\mathrm{C}$ in Figure 15$)$. To the east of the low pressure, rough seas are generated $\left(H_{s} \simeq 4 \mathrm{~m}\right)$, that propagate as swell to the north of the cold atmospheric front (line with triangles). This marine weather situation yields two maxima in the wave-induced pressure. At point $A$ (Figure 15), $F_{p 2 D}$ reaches $2600 \mathrm{hPa}^{2} \mathrm{~m}^{2}$ as the wind-sea interacts with swell from the northwest. The corresponding directional wave spectrum is shown in Figure 1. The weaker maximum to the north at $B$, is due to the interaction of two swells. We note that the highest waves at point
$C$ yield weak pressure fluctuations $\left(200 \mathrm{hPa}^{2} \mathrm{~m}^{2}\right)$ because there is no opposing swell to give a strong contribution to $I(f)$ (equation (3)). If $I(f)$ at $C$ had been the same as at $A$, the wave-induced pressure at $C$ would have been 200 times larger. Minor sources due to shoreline reflections are also predicted, mostly along the Oregon coast. The model was verified at the buoy 46013 (green star) the data of which was processed into directional spectra using the Maximum Entropy Method [Lygre and Krogstad, 1986]. The wave-induced pressure estimated from the buoy data is $110 \mathrm{hPa}^{2} \mathrm{~m}^{2}$, and the local model estimation is $160 \mathrm{hPa}^{2} \mathrm{~m}^{2}$. For 26 January, the estimation of wave heights from the seismic records, using empirical relationships based on average reflectiondominated conditions [Bromirski et al., 1999] yields $H_{s}$ values in the range 8 to $11 \mathrm{~m}$ for this event, depending on the method details, whereas observations did not exceed $5.5 \mathrm{~m}$. This kind of overestimation was already noted by Zopf et al. 
[1976]. This particular seismic record is thus a poor proxy for the coastal ocean wave climate, unless outside information is added. Noise models, such as described here, can help decipher the complex ocean wave patterns from seismic records.

\section{Summary and Perspectives}

[66] Building upon recent improvements in numerical wave modeling and adding a parameterization for wave reflections at shorelines both critical for a proper restitution of the directional wave properties, we have presented the first numerical model of seismic noise that is able to reproduce all three classes of sea states that lead to significant seismic noise levels. These are the generation by a single wind-sea (class I), the generation due to reflections (class II) and the generation due to two opposing wave systems, a wind-sea opposing a swell or two opposing swells (class III) than can be generated by the same moving storm (class IIIa) or by two well separated storms (class IIIb). The only similar previous model, by Kedar et al. [2008], did not include coastal reflections and thus could not reproduce some of the recorded noise events. Although the details of the modeled directional wave spectra cannot be validated to the required level of accuracy for class I generation, and in spite of a simplified seismic propagation model, the consistency of modeled noise with observations demonstrate that our model captures the dominant features of seismic noise generation.

[67] Namely, the strongest noise sources occur in the middle of ocean basins, where crossing wavefields are more common, and where deep enough waters can amplify the wave forcing to a detectable level. This result is consistent with the previous North Atlantic analysis by Kedar et al. [2008]. We further quantified secondary sources, located at the edge of the continental shelf, that are often associated with shoreline reflections, and dominate the records at some seismic stations close to the coast. This is only a summary of a very dynamic and variable field of noise sources which changes on the time scale of a few hours. The high correlation between measured and modeled time series of noise levels demonstrates that the location of sources are well captured by the model. This statement is essentially supported by class III events which are the most intense and require specific oceanic conditions fulfilled only in timedependent and limited areas.

[68] More questions arise on the magnitude of these sources. The model clearly requires a seismic wave damping that, when represented by a quality factor $Q$, varies by at least a factor 2 between oceanic regions around Hawaii and coastal regions off California, with intermediate values in the North Atlantic and southwest Pacific (based on Azores and Easter Island data, not shown). This spatial variation of $Q$ for seismic periods in the range 3 to $10 \mathrm{~s}$ is comparable with estimates from earthquake analysis for periods longer than 30 s [e.g., Mitchell, 1995]. In general $Q$ increases with the age of the crust. Our model also supports a general decrease of $Q$ by a factor 2 to 4 from low $(0.15)$ to high $(0.3 \mathrm{~Hz})$ frequencies.

[69] The shoreline reflections used in the wave model are only expected to provide a correct order of magnitude that will be improved by allowing the reflection to vary spatially and as a function of wave amplitude. Yet the most important limitation of the present model is probably the use of a horizontally uniform seismic model, which means that seismic wave focusing or defocussing and scattering due to crustal heterogeneities are not represented. In reality, these effects likely reduce the noise level at stations in Hawaii and California, explaining why the highest model-observation correlations are found for values of $Q$ that tend to overestimate the observed noise level. Further progress will therefore require the use of more realistic seismic propagation models to quantify this effect. When this is done, the seismic noise might be used to estimate wave model errors on the energy level and directional wave distribution. Figures 5 and 14 already illustrate how the reflection coefficient can be adjusted from buoy data, which was validated here with seismic noise data. The noise data could be used already to perform this adjustment where directional buoy data is not available.

[70] The classification of the noise-generating sea states proposed here should provide a useful guide for a detailed calibration of direct seismic noise models, because the wave model performs differently for different classes. We have also found that this classification helps in the retrieval of wave parameters from seismic noise because the empirical relationships between ocean waves and seismic noise differ for different classes. This will be the topic of another paper.

\section{Appendix A: Derivation of Equation (1) From Hasselmann [1963]}

[71] With our notations and $\sigma=\omega / 2$, equation (2.15) of Hasselmann [1963] gives the spectral density of the equivalent wave-induced pressure at the surface:

$$
F_{p}(\mathbf{K} \simeq 0, \omega)=\rho_{w}^{2} g^{2} \sigma \int_{0}^{2 \pi} f_{\zeta}(\sigma, \theta) f_{\zeta}(\sigma, \theta+\pi) \mathrm{d} \theta .
$$

This is also exactly equation (1) in the work of Webb [2007] in the limit of deep water waves. This can be rewritten in terms of the usual spectral density $F(f, \theta)=f_{\zeta}(\sigma, \theta) /(2 \pi)$, provided by numerical wave models. Also, the directional integral from 0 to $2 \pi$ is equal to twice the integral between 0 and $\pi$, giving

$$
F_{p}(\mathbf{K} \simeq \mathbf{0}, \omega)=\frac{\rho_{w}^{2} g^{2} \sigma}{2 \pi^{2}} \int_{0}^{\pi} F(f, \theta) F(f, \theta+\pi) \mathrm{d} \theta .
$$

Because it is more common to work with spectral densities in frequency, we define $f_{2}=\omega /(2 \pi)$, and $F_{p 3 D}\left(\mathbf{K} \simeq \mathbf{0}, f_{2}\right)=$ $2 \pi F_{p}(\mathbf{K} \simeq \mathbf{0}, \omega)$, and obtain our equation (2).

[72] If there was any doubt on the accuracy or interpretation of equation (2.15) of Hasselmann [1963], it can be lifted by recovering the result of Longuet-Higgins [1950] for monochromatic waves. This requires to specify the seismic wave number $\mathbf{K}$ in order to properly treat the singularity at $\mathbf{K}=\mathbf{0}$ in this case. One thus needs to step back to equation (2.13) in the work of Hasselmann [1963]. We assume from the start that the wave numbers of the two interacting wave trains are nearly opposite $\mathbf{k} \simeq-\mathbf{k}^{\prime}$ to simplify the integrand, we neglect 

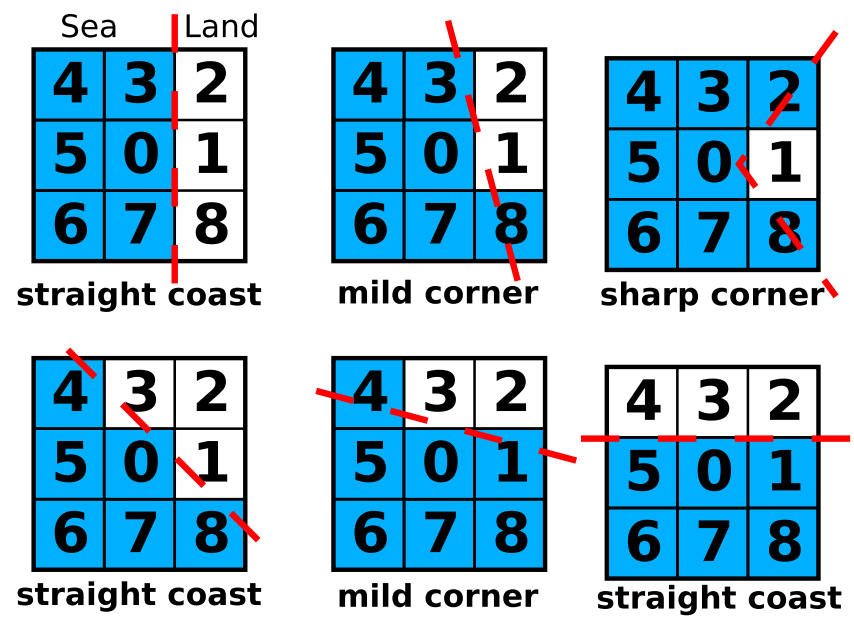

Figure B1. Examples of determination of the shoreline orientation and geometry using the land-sea mask. For any sea point (number 0) which is the ocean (in blue) and has at least one neighbor in land (in white), the eight neighbors, numbered from 1 to 8 , are used to define the shoreline geometry. For mild corners and straight coasts, the estimated shoreline orientation (dashed line) is used to compute the directional distribution of the reflected wave energy.

difference interactions (middle line of his equation (2.13)), and correcting for a few typographic errors, we get

$$
\begin{aligned}
F_{p}(\mathbf{K}, \omega)= & \rho_{w}^{2} g^{4} \int_{-\infty}^{\infty} \int_{-\infty}^{\infty} \int_{-\infty}^{\infty} \int_{-\infty}^{\infty} F_{\zeta}(\mathbf{k}) F_{\zeta}\left(\mathbf{k}^{\prime}\right) \frac{4 k^{2} k^{\prime 2}}{\sigma^{2} \sigma^{\prime 2}} \\
& \cdot \delta\left(\mathbf{k}+\mathbf{k}^{\prime}-\mathbf{K}\right) \delta\left(\sigma+\sigma^{\prime}-\omega\right) \mathrm{d} k_{x} \mathrm{~d} k_{y} \mathrm{~d} k_{x}^{\prime} \mathrm{d} k_{y}^{\prime}
\end{aligned}
$$

where $\delta$ is Dirac's function, and $\sigma$ and $\sigma^{\prime}$ are the radian frequencies of the two interacting wave trains.

[73] Now taking a monochromatic wavefield with variance at two opposite wave numbers $\mathbf{k}_{0}$ and $-\mathbf{k}_{0}$,

$$
F_{\zeta}(\mathbf{k})=E_{1} \delta\left(\mathbf{k}-\mathbf{k}_{0}\right)+E_{2} \delta\left(\mathbf{k}+\mathbf{k}_{0}\right),
$$

we can remove the integral over $k_{x}$ and $k_{y}$ in (19), because the integrand is now only nonzero for $\mathbf{k}=\mathbf{k}_{0}$ and $\mathbf{k}=-\mathbf{k}_{0}$, where $F_{\zeta}(\mathbf{k})$ gives the surface elevation variance $E_{1}$ and $E_{2}$, respectively. Since we are only treating deep-water waves, $\sigma^{2}$ becomes $\sigma_{0}^{2}=g\left|\mathbf{k}_{0}\right|=g k_{0}$, and we get

$$
\begin{aligned}
F_{p}(\mathbf{K}, \omega)= & \rho_{w}^{2} g^{4} \iint\left[E_{1} \delta\left(\mathbf{k}_{0}+\mathbf{k}^{\prime}-\mathbf{K}\right)+E_{2} \delta\left(-\mathbf{k}_{0}+\mathbf{k}^{\prime}-\mathbf{K}\right)\right] \\
& \times \frac{4 k_{0}^{2} k^{\prime 2}}{\sigma_{0}^{2} \sigma^{\prime 2}} F_{\zeta}\left(\mathbf{k}^{\prime}\right) \delta\left(\sigma_{0}+\sigma^{\prime}-\omega\right) \mathrm{d} k_{x}^{\prime} \mathrm{d} k_{y}^{\prime} .
\end{aligned}
$$

We now do the same for $k_{x}^{\prime}$ and $k_{y}^{\prime}$ :

$$
\begin{aligned}
F_{p}(\mathbf{K}, \omega)= & 4 \rho_{w}^{2} g^{4} \frac{k_{0}^{4}}{\sigma_{0}^{4}}\left\{\left[E_{1} E_{2} \delta\left(\mathbf{k}_{0}-\mathbf{k}_{0}-\mathbf{K}\right)\right.\right. \\
& \left.+E_{2} E_{1} \delta\left(-\mathbf{k}_{0}+\mathbf{k}_{0}-\mathbf{K}\right)\right] \\
& \left.+\left[E_{1}^{2} \delta\left(2 \mathbf{k}_{0}-\mathbf{K}\right)+E_{2}^{2} \delta\left(-2 \mathbf{k}_{0}-\mathbf{K}\right)\right]\right\} \delta\left(2 \sigma_{0}-\omega\right)
\end{aligned}
$$

Because there are no seismic waves with both $\mathbf{K}= \pm 2 \mathbf{k}_{0}$ and $\omega=2 \sigma_{0}$, the last two lines are irrelevant, and we get

$$
F_{p}(\mathbf{K}, \omega)=8 \rho_{w}^{2} g^{4} E_{1} E_{2} \delta(\mathbf{K}) \delta\left(2 \sigma_{0}-\omega\right) k_{0}^{4} / \sigma_{0}^{4}
$$

[74] The pressure variance is now given by integrating over the spectral components of the pressure, which naturally removes the Dirac functions, and $g k_{0}$ can be replaced by $\sigma_{0}^{2}$ for deep water waves,

$$
\begin{aligned}
\overline{p_{2}^{2}(t)} & =\int_{0}^{\infty} \int_{-\infty}^{\infty} \int_{-\infty}^{\infty} F_{p}(\mathbf{K}, \omega) \mathrm{d} K_{x} \mathrm{~d} K_{y} \mathrm{~d} \omega \\
& =8 \rho_{w}^{2} \sigma_{0}^{4} E_{1} E_{2} .
\end{aligned}
$$

We can now identify this expression with the variance from Longuet-Higgins's second-order pressure (his equation (31)):

$$
\overline{p_{2}^{2}(t)}=\rho_{w}^{2} 4 a_{1}^{2} a_{2}^{2} \frac{\sigma^{4}}{2}=8 \rho_{w}^{2} \sigma^{4} E_{1} E_{2}
$$

where $E_{1}=a_{1}^{2} / 2$ and $E_{2}=a_{2}^{2} / 2$ are the surface elevation variances of the two interacting wave trains (expressed in $\mathrm{m}^{2}$ when using S.I. units). This variance of the second-order pressure was verified in the laboratory by Cooper and Longuet-Higgins [1951].

\section{Appendix B: Parameterization of Reflections in the Wave Model}

[75] The numerical implementation of reflections was straightforward. In the case of icebergs and subgrid islands, the reflected energy is redistributed evenly in all directions within $90^{\circ}$ of the direction opposite to the incoming waves. This corresponds to a Lambertian surface approximation, which is used for wave scattering from rough surfaces. For resolved lands, a mean direction perpendicular to shore $\theta_{n}$ was defined from the land or sea status of the 8 grid points surrounding the local point (Figure B1).

[76] For each model grid point adjacent to land, the analysis of the land-sea geometry gives one value of $\theta_{n}$ among 16 possible directions. Together with any incoming wave direction $\theta_{i}$ this defines a specular reflection direction $\theta_{r}=2 \theta_{n}-\theta_{i}+\pi$. For each spectral component of direction $\theta_{i}$ going toward the coast (i.e., such that $\cos \left(\theta_{i}-\theta_{n}\right)>0$ ), the total reflection is $R^{2}$ times the incoming energy. This reflected energy $R^{2} E(f) M\left(f, \theta_{i}\right)$ is redistributed over directions around the specular reflection direction $\theta_{r}$, with a broad distribution taken proportional to $\cos ^{n}\left(\theta-\theta_{r}\right)$, where the power $n$ is a function of the local shoreline geometry.

[77] For this purpose we distinguish three different shoreline geometries relative to the local point as illustrated by Figure B1: we set $n=2$ for a straight coast (three connected land points among the neighbors), $n=1$ for a mild corner (two land points among the neighbors), and $n=$ 0 at a sharp corner (only one land point, among the 4 closest neighbors) which corresponds to the same treatment done for subgrid islands and icebergs. Changing these values of $n$ in the range 0 to 2 has little effects on our results. A more rigorous treatment should use the distribution of the shore- 

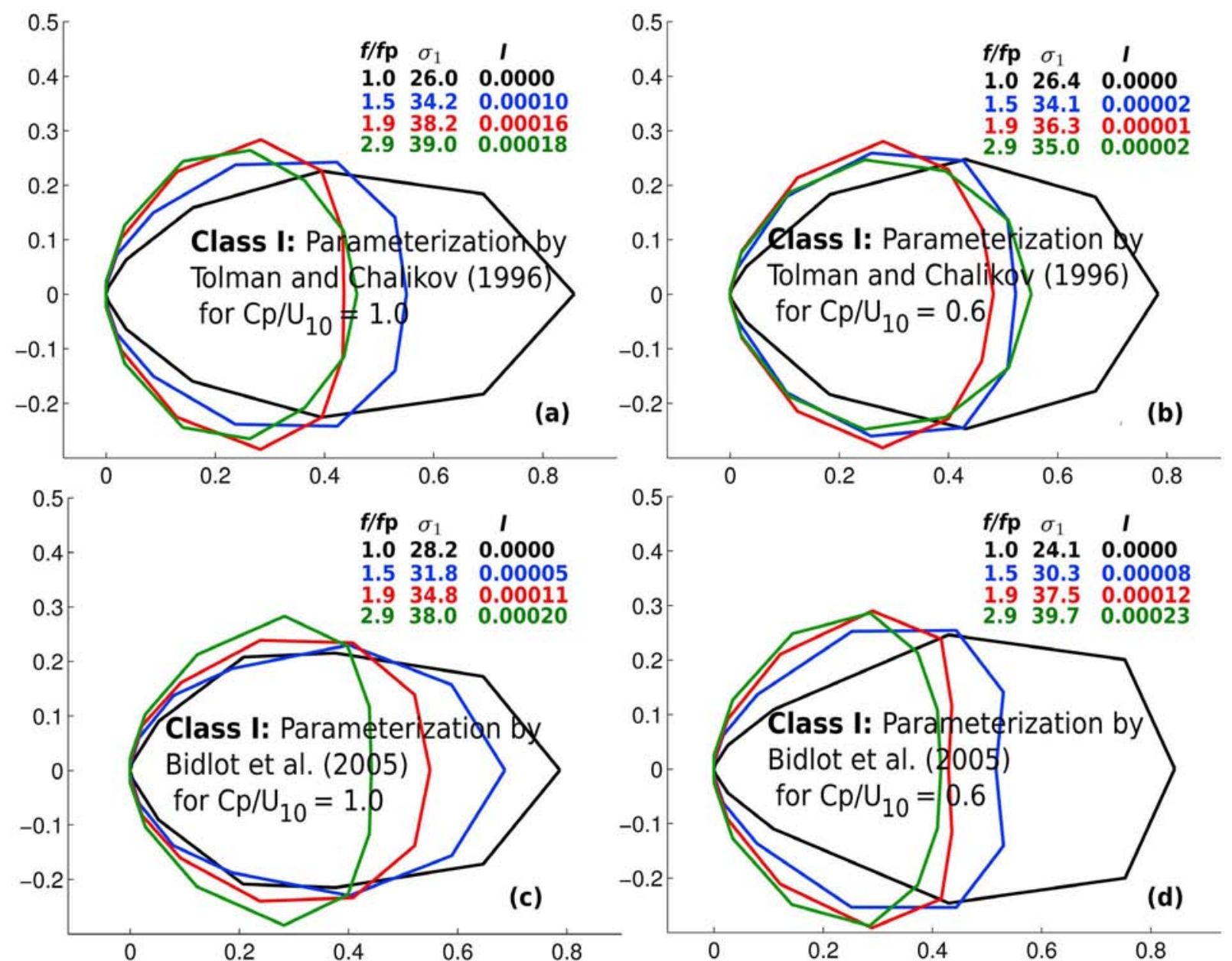

Figure C1. Same as Figure 3, but when using $(\mathrm{a}, \mathrm{b})$ the wave generation and dissipation parameterizations by Tolman and Chalikov [1996], used operationally at the National Oceanic and Atmospheric Administration-National Center for Environmental Prediction, and (c, d) the parameterizations by Bidlot et al. [2005], used operationally at the European Centre for Medium-Range Weather Forecasts.

line orientation at the scale of the ocean wavelength, namely of the order of $100 \mathrm{~m}$.

\section{Appendix C: Sensitivity of Noise Results on Wave Model Parameterization}

[78] The previous work by Kedar et al. [2008] used the same noise generation theory but a different wave model, with wave generation and dissipation parameterizations given by Tolman and Chalikov [1996]. Because so little is known about the directional distribution of wave energy at large oblique angles relative to the mean wave direction, it is important to discuss the impact of different possible choices for wave model parameterizations and numerical schemes. We have thus tested the parameterizations in use today in the two largest operational centers, namely the European Center for Medium range Weather Forecasting, based in Reading, UK [Bidlot et al., 2005], and the U.S. Marine Meteorology Branch (MMAB) of the National Center for Environmental Prediction (NOAA/NCEP) based in Camp Springs, MD [Tolman and Chalikov, 1996]. Results for these two parameterizations are shown in Figure $\mathrm{C} 1$ for the same simple academic case of a uniform wind and ocean.
[79] The striking result is that the values of $I$ obtained with these two parameterizations are at least 1 order of magnitude less than with the present model. In realistic cases the variability of the wind field may compensate for the otherwise narrow spectrum, but we generally expect other parameterizations to give less realistic results for class I generation. This may be the reason why the dynamic range of the seismic noise predicted by Kedar et al. [2008] is much larger than observed, as they probably underestimate the background noise level due to class I generation (see their Figure 6).

[80] The reason for this order of magnitude difference between various parameterizations is that they all use an isotropic dissipation term, except for Ardhuin et al. [2010] who introduced a breaking wave dissipation time scale that varies with the wave direction, on the grounds that waves in the dominant directions are steeper and should break more frequently [Filipot et al., 2010]. This feature was introduced in order to be able to reproduce directional spreadings observed during the SHOWEX experiment [Ardhuin et al., 2007]. For realistic conditions, other model differences play an important role, such as the large bias for 
swell energies when using the parameterizations by Bidlot et al. [2005].

[81] Preliminary comparisons of modeled noise using the wave model parameterizations by Tolman and Chalikov [1996] or Bidlot et al. [2005] suggest that the average noise level may differ by a factor of two compared to our reference simulation, but the correlation with the observed noise time series remain high. There is thus a need for a thorough investigation of these differences, but this goes beyond the scope of the present paper.

[82] Acknowledgments. We thank the operators of GEOSCOPE, Berkeley Digital Seismic Network, and IRIS/IDA for providing excellent broadband seismic data. Data were taken from both GEOSCOPE and IRIS data centers. Wind and wave data were provided by ECMWF, and wave buoy data were taken from the U.S. National Data Buoy Center and the Coastal Data Information Program, while experimental directional spectra were kindly provided by C. Long and D. Resio. A. Balanche performed the spectral analysis of all the seismic stations not shown here but used in our analysis (KDAK, COR, FDF, INU, CMLA, ESK, etc.). F.A. is funded by ERC grant 240009 "IOWAGA" and by the U.S. National Ocean Partnership Program under grant N00014-10-1-0383. M.S. acknowledges the Consolider-Ingeno 2010 (CSD2006-00041, Topo-Iberia). The advice of two anonymous reviewers helped clarify the manuscript.

\section{References}

Ardhuin, F., and R. Magne (2007), Current effects on scattering of surface gravity waves by bottom topography, J. Fluid Mech., 576, 235-264.

Ardhuin, F., T. H. C. Herbers, K. P. Watts, G. P. van Vledder, R. Jensen, and H. Graber (2007), Swell and slanting fetch effects on wind wave growth, J. Phys. Oceanogr., 37, 908-931, doi:10.1175/JPO3039.1.

Ardhuin, F., L. Marié, N. Rascle, P. Forget, and A. Roland (2009), Observation and estimation of Lagrangian, Stokes and Eulerian currents induced by wind and waves at the sea surface, J. Phys. Oceanogr., 39, $2820-2838$.

Ardhuin, F., et al. (2010), Semi-empirical dissipation source functions for wind-wave models: Part I, definition, calibration and validation, J. Phys. Oceanogr., 40, 1917-1941.

Ardhuin, F., J. Tournadre, P. Queffelou, and F. Girard-Ardhuin (2011), Observation and parameterization of small icebergs: Drifting breakwaters in the Southern Ocean, Ocean Modell., doi:10.1016/j.ocemod.2011. 03.004, in press.

Banner, M. L. (1990), Equilibrium spectra of wind waves, J. Phys. Oceanogr., 20, 966-984.

Bernard, P. (1941), Sur certaines proprietes de la boule etudiées a l'aide des enregistrements seismographiques, Bull. Inst. Oceanogr. Monaco, 800, $1-19$.

Bidlot, J.-R. (2009), Intercomparison of operational wave forecasting systems against buoys: Data from ECMWF, MetOffice, FNMOC, NCEP, DWD, BoM, SHOM and JMA, September 2008 to November 2008 , technical report, Joint World Meteorol. Organ.-Int. Ozone Comm. Tech. Comm. for Oceanogr. and Mar. Meteorol., Paris.

Bidlot, J., S. Abdalla, and P. Janssen (2005), A revised formulation for ocean wave dissipation in CY25R1, Tech. Memo. R60.9/JB/0516, Res. Dep. Eur. Cent. for Medium-Range Weather Forecasts, Reading, U. K.

Bromirski, P. D., R. E. Flick, and N. Graham (1999), Ocean wave height determined from inland seismometer data: Implications for investigating wave climate changes in the NE Pacific, J. Geophys. Res., 104, 20,753-20,766, doi:10.1029/1999JC900156.

Chevrot, S., M. Sylvander, S. Benahmed, C. Ponsolles, J. M. Lefèvre, and D. Paradis (2007), Source locations of secondary microseisms in western Europe: Evidence for both coastal and pelagic sources, J. Geophys. Res., 112, B11301, doi:10.1029/2007JB005059.

Cooper, R. I. B., and M. S. Longuet-Higgins (1951), An experimental study of the pressure variations in standing water waves, Proc. R. Soc. London Ser. A, 206, 426-435, doi:10.1098/rspa.1951.0079.

Delpey, M., F. Ardhuin, F. Collard, and B. Chapron (2010), Space-time structure of long swell systems, J. Geophys. Res., 115, C12037, doi:10.1029/2009JC005885.

Donelan, M. A., J. Hamilton, and W. H. Hui (1985), Directional spectra of wind-generated waves, Philos. Trans. R. Soc. London Ser. A, 315 509-562.

Dziewonski, A. M., and D. L. Anderson (1981), Preliminary reference Earth model, Phys. Earth Planet. Inter., 25, 297-356.
Elgar, S., T. H. C. Herbers, and R. T. Guza (1994), Reflection of ocean surface gravity waves from a natural beach, J. Phys. Oceanogr., 24, 1503-1511.

Farrell, W. E., and W. Munk (2008), What do deep sea pressure fluctuations tell about short surface waves?, Geophys. Res. Lett., 35, L19605, doi:10.1029/2008GL035008.

Filipot, J.-F., F. Ardhuin, and A. Babanin (2010), Parameterization of wave breaking and spectral modeling of sea states, Ph.D. thesis, Univ. Eur. de Bretagne, Brest, France.

Gelci, R., H. Cazalé, and J. Vassal (1957), Prévision de la houle: La méthode des densités spectroangulaires, Bull. Inf. Com. Oceanogr. Etude Côtes, 9 , 416-435.

Gerstoft, P., M. C. Fehler, and K. G. Sabra (2006), When Katrina hit California, Geophys. Res. Lett., 33, L17308, doi:10.1029/2006GL027270.

Hanson, J. L., and O. M. Phillips (2001), Automated analysis of ocean surface directional wave spectra, J. Atmos. Oceanic Technol., 18, 277-293.

Hasselmann, K. (1963), A statistical analysis of the generation of microseisms, Rev. Geophys., 1, 177-210, doi:10.1029/RG001i002p00177.

Haubrich, R. A., and K. McCamy (1969), Microseisms: Coastal and pelagic sources, Bull. Seismol. Soc. Am., 7, 539-571.

Hughes, B. (1976), Estimates of underwater sound (and infrasound) produced by nonlinearly interacting ocean waves, J. Acoustic Soc. Am., 60, 1032-1039.

Kanamori, H., and J. W. Given (1981), Use of long-period surface waves for rapid determination of earthquake-source parameters, Phys. Earth Planet. Inter., 27, 8-31.

Kedar, S., M. Longuet-Higgins, F. W. N. Graham, R. Clayton, and C. Jones (2008), The origin of deep ocean microseisms in the North Atlantic Ocean, Proc. R. Soc. London Ser. A, 464, 1-35, doi:10.1098/ rspa.2007.0277.

Koper, K. D., K. Seats, and H. Benz (2010), On the composition of Earth's short-period seismic noise field, Bull. Seismol. Soc. Am., 100, 606-617, doi:10.1785/0120090120.

Kuik, A. J., G. P. van Vledder, and L. H. Holthuijsen (1988), A method for the routine analysis of pitch-and-roll buoy wave data, J. Phys. Oceanogr., $18,1020-1034$

Long, C. E., and D. T. Resio (2007), Wind wave spectral observations in Currituck Sound, North Carolina, J. Geophys. Res., 112, C05001, doi:10.1029/2006JC003835.

Longuet-Higgins, M. S. (1950), A theory of the origin of microseisms, Proc. R. Soc. London Ser. A, 243, 1-35.

Lygre, A., and H. E. Krogstad (1986), Maximum entropy estimation of the directional distribution in ocean wave spectra, J. Phys. Oceanogr., 16, 2052-2060.

Mei, C. C. (1989), Applied Dynamics of Ocean Surface Waves, 2nd ed., 740 pp., World Sci., Singapore.

Miche, A. (1944), Mouvements ondulatoires de la mer en profondeur croissante ou décroissante: Première partie. Mouvements ondulatoires périodiques et cylindriques en profondeur constante, Ann. Ponts Chaussées, $114,42-78$.

Mitchell, B. J. (1995), Anelastic structure and evolution of the continental crust and upper mantle from seismic surface wave attenuation, Rev. Geophys., 33, 441-462, doi:10.1029/95RG02074.

Mooney, W., G. Laske, and G. Masters (1998), Crust 5.1: A global crustal model at $5^{\circ} \times 5^{\circ}, J$. Geophys. Res., 103, 727-747, doi:10.1029 97JB02122.

O'Reilly, W. C., T. H. C. Herbers, R. J. Seymour, and R. T. Guza (1996), A comparison of directional buoy and fixed platform measurements of Pacific swell, J. Atmos. Oceanic Technol., 13, 231-238.

O'Reilly, W. C., R. T. Guza, and R. J. Seymour (1999), Wave prediction in the Santa Barbara channel, final technical summary/final study report, Miner. Manage. Serv., Santa Barbara, Calif.

Pawka, S. S. (1983), Island shadows in wave directional spectra, J. Geophys. Res., 88, 2579-2591, doi:10.1029/JC088iC04p02579.

Rogers, W. E., P. A. Wittmann, D. W. C. Wang, R. M. Clancy, and Y. L. Hsu (2005), Evaluations of global wave prediction at the Fleet Numerical Meteorology and Oceanography Center, Weather Forecasting, $20,745-760$.

Savage, B., D. Komatitsch, and J. Tromp (2010), Effects of 3D attenuation on seismic wave amplitude and phase measurements, Bull. Seismol. Soc. Am., 100, 1241-1251, doi:10.1785/0120090263.

Stutzmann, E., G. Roult, and L. Astiz (2000), Geoscope station noise level, Bull. Seismol. Soc. Am., 90, 690-701.

Stutzmann, E., M. Schimmel, G. Patau, and A. Maggi (2009), Global climate imprint on seismic noise, Geochem. Geophys. Geosyst., 10, Q11004, doi:10.1029/2009GC002619

Tanimoto, T. (2010), Equivalent forces for colliding ocean waves, Geophys. J. Int., 181, 468-478, doi:10.1111/j.1365-246X.2010.04505.x. 
Tolman, H. L. (1991), A third generation model for wind on slowly varying, unsteady and inhomogeneous depth and currents, J. Phys. Oceanogr., 21, 766-781.

Tolman, H. L. (2009), User manual and system documentation of WAVEWATCH-III ${ }^{\mathrm{TM}}$ version 3.14, Tech. Rep. 276, Natl. Oceanic and Atmos. Admin., Camp Springs, Md.

Tolman, H. L., and D. Chalikov (1996), Source terms in a third-generation wind wave model, J. Phys. Oceanogr., 26, 2497-2518.

Tournadre, J. (1993), Time and space scales of significant wave heights, J. Geophys. Res., 98, 4727-4738, doi:10.1029/92JC02625.

Tournadre, J., K. Whitmer, and F. Girard-Ardhuin (2008), Iceberg detection in open water by altimeter waveform analysis, J. Geophys. Res., 113, C08040, doi:10.1029/2007JC004587.

van Vledder, G. P., and L. H. Holthuijsen (1993), The directional response of ocean waves to turning winds, J. Phys. Oceanogr., 23, 177-192.

Wait, J. R. (1966), Theory of HF ground wave backscatter from sea waves, J. Geophys. Res., 71, 4839-4842.

Webb, S. C. (2007), The Earth's "hum" is driven by ocean waves over the continental shelves, Nature, 445, 754-756, doi:10.1038/nature05536.

Wessel, P., and W. H. F. Smith (1996), A global self-consistent hierarchical, high-resolution shoreline database, J. Geophys. Res., 101, 8741-8743.
Wiechert, E. (1904), Discussion, verhandlung der zweiten Internationalen Seismologischen Konferenz, Beitrage Geophys., 2, 41-43.

WISE Group (2007), Wave modelling-The state of the art, Prog. Oceanogr., 75, 603-674, doi:10.1016/j.pocean.2007.05.005.

Zopf, D. O., H. C. Creech, and W. H. Quinn (1976), The wavemeter: A land-based system for measuring nearshore ocean waves, Mar. Technol. Soc. J., 10, 19-25.

F. Ardhuin, Laboratoire d'Océanographie Spatiale, Institut Français de Recherche pour l'Exploitation de la Mer, Centre de Brest, BP 70, F-29280 Plouzané, France. (ardhuin@ifremer.fr)

A. Mangeney, Departement de Sismologie, Institut de Physique du Globe de Paris, Université Paris VII - Denis Diderot, Sorbonne Paris-Cité, 4 Place Jussieu, Case 89, F-75005 Paris, France.

M. Schimmel, Department of Structure and Dynamics of the Earth, Institute of Earth Sciences Jaume Almera, Consejo Superior de Investigaciones Científicas, Lluis Sole i Sabaris s/n, E-08028 Barcelona, Spain.

E. Stutzmann, Departement de Sismologie, Institut de Physique du Globe de Paris, Sorbonne Paris-Cité, 4 Place Jussieu, F-75005 Paris, France. 